AFCRC-TN-56-799

ASTIA DOCUMENT No. AD110140

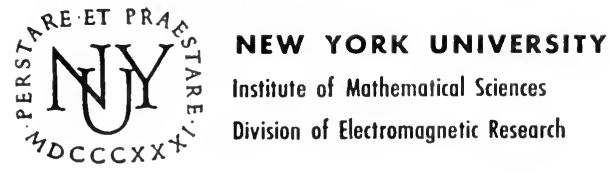

RESEARCH REPORT NO. EM-100

\title{
Asymptotic Expansion of Multiple Integrals and the Method of Stationary Phase
}

DOUGLAS S. JONES and MORRIS KLINE

CONTRACT No. AF 19(604)1717

OCTOBER 1956 

NEW YOPK. UNIVERSTTY

Institute of Mathematical sciences

Division of Electromagnetic Research

Research Report No. EM-100

ASYMPTOTIC EXPANSION OF MULTIPLE INTEGRALS AND

THE METHOD OF STATIONARY PHASE

Douglas S. Jones and Morris Kline

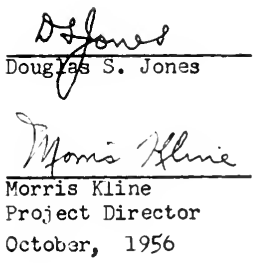

The research reported in this document has been made possible through support and sponsorship extended by the Air Force Cambridge Research Center, under Contract No. Af19(604)1717. It is published for technical information only and does not necessarily represent. recommendations or conclusions of the sponsoring agency.

New York, 1956 


\section{Table of Contents}

1. Introduction

2. Reduction of the problem to the single integral case 4

3. The behavior of $h(t)$ at ordinary points of $D \quad 10$

4. Contributions from critical, non-stationary boundary points 14

5. Contributions from interior stationary points 22

6. Contributions from boundary stationary points 32

7. Remarks on the method 36

$\begin{array}{ll}\text { Appendix } & 38\end{array}$

References $\quad 43$

Distribution List

\section{Abstract}

This paper considers the asymptotic evaluation of the double integral

$$
\iint_{D} g(x, y) e^{i k f(x, y)} d y d x
$$

for large $k$. The domain $D$ is finite and the functions $g$ and $f$ are assumed to be analytic iri and on the boundary of $D$. Under these conditions certain points $(x, y)$ of $D$, called critical points, prove to be decisive. The asymptotic form of the double integral is given by the sum of asymptotic series in integra 1 and fractional powers of $1 / k$, and each of these series is determined by a neighborhood in $D$ of a critical point. The method of this paper is the essentially new feature. The problem of evaluating the double integral asymptotically is reduced to the problem of evaluating a single Fourier integral asymptotically and known results for the latter case are applied. 



\section{Introduction}

In problems of the diffraction theory of optics as well as in many microwave problems a solution is obtained in the form

$$
J=\iint_{D} g(x, y) e^{i k f(x, y)} d y d x,
$$

wherein $g$ and $f$ are real functions and generally $k$ is real. Physically, $g(x, y)$ is an amplitude function, $f(x, y)$ is a phase function and $k=2 \pi / \lambda$, $\lambda$ being the wavelength of some source which gives rise to the field represented by the double integral. It is usually impossible to evaluate integrals of this form explicitly. In the applications mentioned above one is interested in the value of the integral for small wavelength, that is, large $\mathrm{k}^{\text {*it }}$. Hence in recent years attention has been focused on the problem of obtaining an asymptotic series representation of $\mathrm{J}$ in integral and fractional powers of $1 / \mathrm{k}$.

To obtain such a result Van Kampen $[4]$ applied the method of stationary phase, originally developed for single integrals, in a purely formal manner. It is clear from the formal uses of the method of stationary phase that the asjmptotic series representation of (I) is a sum of asymptotic series determined by the behavior of $f(x, y)$ in the neighborhood of certain critical points of the domain $D$ of integration.

Recently Focke[6] gave a rigorous treatment of the asymptotic expansion of $\mathrm{J}$ in wich he includes a number of types of critical points not previously treated.. He uses the notion of a neutralizer originally introduced $b$ van der Corput for single integrals and extended by Focke to double integrals. The neutralizer is a function of $x$ and $y$ which serves the purpose of isolating the various critical points so that one might determine the contributin each makes to the asymptotic

* See, for example, the roview articles by E. Wolf [l] and H. Bremer [2] and also a recent thesis by J. Berghuis [3].

** The case of small $\mathrm{k}$ is also of practical interest in optics. See the work of K. Nienhuis and B.R.A. Nijboer, referred to by Wolf[I]. 
evaluation of the double integral.

Both Focke and the present paper assume that the functions $g$ and $f$ of the integral are analytic in and on the boundary of the region D. Braun [10], using the method of van der Corput, assumes only that $f$ and $g$ have a finite number of continuous derivatives; he obtains explicit results only for some types of interior critical points, and indicates the method to be employed for some boundary critical points. The method and the results are complicated but may be the best obtainable on the basis of his weaker assumptions. A number of special results on the asymptotic evaluation of the integral $\mathrm{J}$ obtained by Berghuis [3], Bremer [5], Siegel [12], and Kontorovitch and Muravév [14] are germene. Mention should also be made of a forthcoming report by $N$. Chako who is pursuing other methods of evaluating the integral I asymptotically.

The present paper is designed to show that the asymptotic expansion of the integral $\mathrm{J}$ can be reduced almost at once to the asymptotic expansion of single Fourier integrals, that is, integrals of the form

$$
\int_{\alpha}^{\beta} h(t) e^{i k t} d t,
$$

wherein $h(t)$ and $k$ are real. The asymptotic expansion of such integrals and of the more general integrals

$$
\int_{\alpha}^{\beta} h(t) e^{i k g(t)} d t
$$

has been extensively investigated. However, using the notion of a neutralizer and integration by parts, Erdélyi [7] has given a direct proof of the key theorem on asymptotic expansion of integrals of the forms (2) and (3). The theorem of Erdélyi, which deals with integrals of the form (2) and on which this paper rests, reads as follows: 
Theorem. If $\phi(t)$ is $\mathrm{N}$ times continuously differentiable for $a \leq t \leq \beta$, and $0<\lambda \leq 1,0<\mu \leq 1$, then

$$
\int_{\alpha}^{\beta} e^{i k t}(t-\alpha)^{\lambda-1}(\beta-t)^{\mu-1} \phi(t) d t=B_{N}(k)-A_{N}(k)+O\left(k^{-N}\right) \text { as } k \rightarrow \infty \text {, }
$$

where

$$
\begin{aligned}
& A_{N}(k)=\sum_{n=0}^{N-1} \frac{\Gamma(n+\lambda)}{n !} e^{1 n(n+\lambda-2) / 2} k^{-n-\lambda} e^{1 k \alpha} \frac{d^{n}}{d a^{n}}\left[(\beta-\alpha)^{\mu-1} \emptyset(a)\right] \\
& B_{N}(k)=\sum_{n=0}^{N-1} \frac{\Gamma(n+\mu)}{n !} e^{i n(n-\mu) / 2} k^{-n-\mu} e^{1 k \beta \frac{d^{n}}{d \beta^{n}}\left[(\beta-\alpha)^{\lambda-1} \emptyset(\beta)\right],} \\
& \text { and } O\left(k^{-N}\right) \text { may be replaced by o(k-iN) if } \lambda=\mu=1 .
\end{aligned}
$$

If the original integral (2) is to be considered over a larger domain $a \leq a<\beta \leq b$, then, of course, it is to be decomposed into subdomains in each of which the above theorem applies. Also if $\phi(t)$ is infinitely differentiable within $\alpha<t<\beta$ then $A_{N}(k)$ and $B_{N}(k)$ become infinite series and the order of the remainder becomes less than any power of $1 / k$.

The method of this paper is certainly no more complicated than Focke's. Moreover it seems to have several advantages. The analysis shows how the behavior of the contour lines of $f(x, y)$, that is, the lines $f(x, y)=$ const., determines the critical points. These lines have imnediate physical significance. In diffraction optics $f(x, y)$ represents an optical distance from the source to a given point in the image space along a ray whose first two direction cosines in the inage space are $\mathrm{x}$ and $\mathrm{y}$. It is therefore possible with the present theory to predict the types of critical points from a knowledge of the rays and to interpret the contribution of each critical point in terms of the behavior of rays. Secondly, the calculation of the successive coefficients of the various asymptotic series arising from the several critical points is simpler in the present case. Thirdly, the reduction of 
the problem of asymptotic expansion of higher dimensional multiple integrals of the form (1) to that of single integrals is immediately effected by the method of this paper.

2. Reduction of the problem to the single integral case

We consider integrals of the form

$$
J=\iint_{D} g(x, y) e^{i k f(x, y)} d x d y,
$$

where $g$ and $f$ are real analytic functions, thus possessing derivatives of all orders, at all points interior to and on the boundary of $D$. The boundary of $D$ is assumed to be piecewise infinitely differentiable, and such that if $\phi(x, y)=0$ is a representation of any piece, $\phi_{\mathrm{x}}$ and $\phi_{\mathrm{y}}$ are both zero at any point on the boundary. We shall take $k$ to be real, though the simpler case of complex $k$ is actually included, as noted below.

Let $m$ and $M$ be the smallest and largest values attained by $f(x, y)$ in $D$ so that $m \leq f(x, y) \leq M$ for $x$, $y$ in $D$. Then, for $\varepsilon>0$,

$$
e^{i k f}=\int_{m-\varepsilon}^{M+\varepsilon} e^{i k t} \delta(t-f) d t .
$$

Hence

$$
J=\iint_{D} g e^{i k f} d x d y=\iint_{D} g \int_{m-\varepsilon}^{M+\varepsilon} e^{i k t} \delta(t-f) d t d x d y \cdot
$$

By an interchange of the order of integration we obtain

$$
J=\int_{m-\varepsilon}^{M+\varepsilon} e^{1 k t} \iint_{D} g \delta(t-f) d x d y d t,
$$

Fe write $m-\varepsilon$ and $M+\varepsilon$ merely to emphasize that the behavior of $f$ at the end-points $\mathrm{m}$ and $\mathrm{M}$ is significant. 
or

$$
J=\int_{m-\varepsilon}^{M+\varepsilon} e^{i k t} h(t) d t,
$$

where

$$
h(t)=\iint_{D} g(x, y) \delta\{t-f(x, y)\} d x d y
$$

Thus the problem of obtaining the asymptotic behavior of $J$ is reduced to that of evaluating the single Fourier integral on the right side of equation (7). The same reduction is obviously possible in the case of integrals of several variables.

It follows from Erdélyi's theorem that there are contributions to the asymptotic expansion of an integral of the form (7) only from those critical values of $t$, possibly including the end points $m$ and $M$, at which $h(t)$ or any derivative is discontinuous or at which $h(t)$ or any derivative becomes infinite. In the case of infinities the theorem gives the form of the expansion only for integrable algebraic singularities of $h(t)$. The case of a logarithmic infinity in $h(t)$ will also be needed and will be treated separately in the Appendix ${ }^{*}$. Since for the $h(t)$ of this paper, namely $(8)$ above, $h(m-\varepsilon)=h(M+\varepsilon)=0$, we need consider just those values of $t$ within the closed interval $(m, M)$.

It is intuitively clear - the precise analysis will be given later - that the behavior of $h(t)$ at any value $t_{0}$ of $t$ will depend upon the beharior of the contour lines $f(x, y)=t$ for $t$ near and at $t_{0}$. Moreover, on the contour line $f(x, y)=t_{0}$ only certain points and their neighborhoods will be significant. For example, if at an interior point $\left(x_{0}, y_{0}\right)$ of $D$ at least one of the partial derivatives $f_{x}$ and $f_{y}$ is not zero, then the contour lines through $\left(x_{0}, y_{0}\right)$ and points in a small neighborhood will be smooth and change smoothly with $t$, so that $h(t)$ and its successive derivatives will be continuous insofar as contributions to $h(t)$ from this neighbor hood *Independently, A. Erdélyi has extended his theorem to the case of logarithmic singularities of $h(t)$ in (2) and (3). His results and the results of our Appendix overlap. His results appear in the Journal of the Society for Industrial and Applied Mathematics, March, 1956. 
of $\left(x_{0}, y_{0}\right)$ are concerned. On the other hand, if $\left(x_{0}, y_{0}\right)$ is a relative maximum point of $f(x, y)$, so that $f_{x}$ and $f_{y}$ are zero there, then $h(t)$ will be zero for $t>t_{0}$ insofar as contributions to $h(t)$ from a neighborhood of $\left(x_{0}, y_{0}\right)$ are concerned, and $h(t)$ may well be analytic for $t<t_{0}{ }^{\circ}$ In any case $h(t)$ will not be analytic at $t=t_{0}$. In other words, the non-analyticity of $h(t)$ at any value $t_{0}$ of $t$ will depend upon the behavior of the contour lines $f(x, y)=t$ only in the neighborhoods of certain points $\left(x_{0}, y_{0}\right)$, called critical points, a fact already observed in earlier formal treatments of the asymptotic expansion of J. Similar remarks apply to integrals of more than two variables when the curves $f=$ const. are replaced by surfaces or hypersurfaces $f=$ const.

When $\mathrm{k}$ is complex and $0<\arg \mathrm{k}<\pi$, it is necessary to consider the behavior of $h(t)$ only near $t=m$ because the contributions from other points are exponentialIy small compared with the expansion obtained from $t=m$. Thus we evaluate the integral expression (8) for $h(t)$ near $t=m$ and, on account of the presence of the ס-function, we need use only a neighborhood of $f=m$. The behavior of the contour lines $f(x, y)=$ const. in this neighborhood will determine the asymptotic expansion. When $-\pi<\arg k<0$, we need consider only the behavior of $h(t)$ near $t=M$.

Since, as is indicated by the preceding intuitive evidence, the significant behavior of $h(t)$ will depend upon its behavior in the neighborhoods of certain critical points of $D$ we shall develop same new forms for $h(t)$ which will be useful in discussing its behavior in small regions of $D_{\text {. Let }} D_{0}$ be any (small) subdomain of $D$ and let us introduce a coordinate transformation, whose nature will be specified later, from $x, y$ to $X, Y$. Let $f(x, y)$ transform to $F(X, Y)$ and let the product of $g(x, y)$ and the Jacobian of the transformation transform to $G(X, Y)$. Then, letting $h_{0}(t)$ represent the value of $h(t)$ over $D_{0}$, we have

$$
h_{0}(t)=\iint_{D_{0}} G(X, Y) \delta\{t-F(X, Y)\} d X d Y .
$$




$$
F(X, Y)=F_{0}(X, Y)+F_{I}(X, Y)
$$

and introduce the new variables

$$
\xi=F_{0}(X, Y), \quad \eta=Y(X, Y),
$$

where $Y$ is at our disposal. Let $\hat{f}_{1}(\xi, \eta)$ and $y(\xi, \eta)$ be the functions which result from $F_{I}$ and $G$ under this change of variables. Then

$$
h_{0}(t)=\iint_{D_{0}} y(\xi, \eta) \frac{\partial(x, Y)}{\partial(\xi, \eta)} \delta\left\{t-\xi-\hat{f}_{1}(\xi, \eta)\right\} d \xi d \eta,
$$

where $D_{0}$ now represents the $(\xi, \eta)$ domain corresponding to the original $(X, Y)$ domain.

We apply Taylor's theorem to the $\delta$-iunction in (10) and expand around $t=\xi$ with $-\mathcal{F}_{1}$ as the increment. Then

$$
h_{0}(t)=\sum_{r=0}^{\infty} \iint_{D_{0}} \frac{(-1)^{r}}{r l} \not(\xi, \eta) \frac{\partial(X, Y)}{\partial(\xi, \eta)} \mathcal{f}_{1}^{r}(\xi, \eta) \delta(r)(t-\xi) d \xi d \eta,
$$

where $\delta^{(r)}$ indicates the $r$-th derivative of $\delta(t-\xi)$.

It may be helpful towards understanding later steps if before transforming further we examine the meaning of the equation just obtained. The right side is a sum of terms of the form

$$
\iint_{0} \#(\xi, \eta) \delta^{(r)}(t-\xi) d \xi d \eta
$$

The double integral may be regarded as a repeated integral with respect to $\xi$ and then with respect to $\eta$. Hence the inner integral is of the form

$$
\int_{\xi_{1}(c)}^{\xi_{2}(c)} H(\xi, c) \delta^{(r)}(t-\xi) d \xi,
$$


where $\xi_{1}(c)$ and $\xi_{2}(c)$ are the least and greatest values of $\xi$ for $\eta=c$ in the domain $D_{0}$. By utilizing a property of the $\delta$-function $[9]$ we may convert this integral to some function $K(t, \eta)$ and we must then consider

$$
\int_{\eta_{1}}^{\eta_{1}} k(t, \eta) d \eta
$$

where $\eta_{1}$ and $\eta_{2}$ are the least and greatest values of $\eta$ in all the $(\xi, \eta)$ for which $\xi=t$. For arbitrary $t, \eta_{1}$ and $\eta_{2}$ will be functions of $t$.

If we proceed to transform equation (II) in the manner indicated, we shall encounter some difficulty*. Instead we shall reverse the order of integration in (12). Thus

The difficulty we seek to avoid is the following. Let us consider the term in (1I) when $r=1$. We should now use the relevant property of the $\delta$-function

$$
\int_{a}^{b} f(x) \delta^{\prime}(t-x) d x=f^{\prime}(t)+f(a) \delta(t-a)-f(b) \delta(t-b)
$$

This is obtained by integration by parts from the equation defining the 6-function, namely,

$$
\left.\int_{a}^{b} f(x) \delta t-x\right) d x=f(t)
$$

When apply the above property to the case $r=1$ in (13) we obtain

$$
H_{t}(t, \eta)+H\left(\xi_{1}(c), \eta\right) \delta\left(t-\xi_{I}(c)\right)-H\left(\xi_{2}(c), \eta\right) \delta\left(t-\xi_{2}(c)\right)
$$

If we now integrate with respect to $\eta$, the second and third terms may contribute to the result because c must now be replaced by $\eta$. For $r>I$, the difficulties In this procedure become considerably greater. 


$$
\begin{aligned}
\iint_{D_{0}} N(\xi, \eta) \delta^{(r)}(t-\xi) d \xi d \eta & =\int_{\xi_{1}}^{\xi_{2}} \delta(r)(t-\xi) \int_{\eta_{1}(\xi)}^{\eta_{2}(\xi)} N(\xi, \eta) d \eta d \xi ; \\
& =\int_{\xi_{1}}^{\xi_{2}} \delta^{(r)}(t-\xi) K(\xi) d \xi ; \\
& =\frac{\partial^{r}}{\partial t^{r}} K(t)^{*} ; \\
& =\frac{\partial^{r}}{\partial t^{r}} \int_{\eta_{1}(t)}^{\eta_{2}(t)} H(t, \eta) d \eta
\end{aligned}
$$

If we apply this result to each term of (1]) we obtain the result

$$
h_{0}(t)=\sum_{r=0}^{\infty} \frac{\partial^{r}}{\partial t^{r}} \int_{\eta_{1}(t)}^{\eta_{2}(t)} \frac{(-1)^{r}}{r !} H(t, \eta) \frac{\partial(x, y)}{\partial(t, \eta)} \exists_{1}^{r}(t, \eta) d \eta .
$$

Formula (14) for $h_{0}(t)$ is basic in the subsequent calculations. Its merit as opposed to that of formula (8) is that the path of integration is now $t=\xi$ instead of $t=f(x, y)$. However it will be convenient to introduce one or two variations of 1 t. By reason of the analyticity of $f$ and $g$ we can say that in the neighborhood of any point $\left(\mathrm{x}_{0}, \mathrm{Y}_{0}\right)$, which corresponds to $\left(\mathrm{x}_{0}, \mathrm{y}_{0}\right)$, the following absolutely convergent expansions hold:

This result is valid for $t$ between $\xi_{1}$ and $\xi_{2}$. There will be a few cases in which we shall want the behavior of $h_{0}(t)$ at $t=\xi_{1}$ or $t=\xi_{2}$. However, $h_{0}(t)$ will be singular at such values of $t$. But the behavior at $t=\xi_{1}+$ or $t=\xi_{2}-$, which is what will actually be needed later, is determined by the behavior of $h_{0}(t)$ for $t>\xi_{1}+$ or $t<\xi_{2}-$. Hence we need not consider the value of $h_{0}(t)$ for $t=\xi_{1}$ or $t=\xi_{2}$. 


$$
G(X, Y)=\sum_{m=0}^{\infty} \sum_{n=0}^{\infty} G_{m, n}\left(X-X_{0}\right)^{m}\left(Y-Y_{0}\right)^{n}
$$

and

$$
\frac{(-I)^{r}}{r \downarrow} F_{I}^{r}(X, Y)=\sum_{p=0}^{\infty} \sum_{q=0}^{\infty} F_{r, p, q}\left(X-X_{0}\right)^{p}\left(Y-Y_{0}\right)^{q} .
$$

Therefore

$$
\frac{(-I)^{r}}{r !} G(X, Y) F_{I}^{r}(X, Y)=\sum_{\lambda=0}^{\infty} \sum_{\mu=0}^{\infty}\left(X-X_{0}\right)^{\lambda}\left(Y-Y_{0}\right)^{\mu} \sum_{p=0}^{\lambda} \sum_{q=0}^{\mu} G_{\lambda-p, \mu-q} F_{r, p, q} .
$$

If we now introduce the variables $\xi, \eta$ of (9) in place of $X, Y$ and then write $t$ for $\xi$ we shall have the integrand required in ( $\left.\omega_{1}\right)$, apart from the Jacobian. If, in particular, it should be the case in (9) that

$$
X-x_{0}=\xi_{1}(\xi) \eta_{1}(\eta) \text { and } Y-Y_{0}=\xi_{1}(\xi) \eta_{2}(\eta)
$$

then (15) becomes

$$
\frac{(-1)^{r}}{r !} B(\xi, \eta) \mathcal{F}_{1}^{r}(\xi, \eta)=\sum_{\mu=0}^{\infty} \xi_{I}^{\mu} \sum_{\lambda=0}^{\mu} \eta_{1}^{\lambda} \eta_{2}^{\mu-\lambda} \sum_{p=0}^{\lambda} \sum_{q=0}^{\mu-\lambda} G_{\lambda-p, \mu-\lambda-q} F_{r, p, q},
$$

and, if we replace $\xi$ by $t$, we again have the form of the integrand required in formula (14), except for the Jacobian.

\section{The tehavior of $h(t)$ at ordinary points of $D$}

We propose now to characterize the critical points $(x, y)$ of $D$, to show that if $f(x, y)=t$ contains the critical point then $h(t)$ is analytic, and to prove that if $(x, y)$ is a critical point then the resulting non-analytic form of $h(t)$ is determined by an arbitrarily small neighborhood of $(x, y)$.

Let us label as ordinary or non-critical, those interior points $(x, y)$ of $D$ at which at least one of $f_{x}$ and $f_{y}$ is not zero and those boundary points at which the same condition holds, the boundary is analytic, and $f(x, y)=$ const. is 
neither tangent to nor coincident with the bcundary. All other points or arcs (in the case of coincidence of part of $f(x, y)=$ const. with the boundary) will be called critical points or arcs. We shall assume that the number of these critical points or arcs is finite.

Now let $t_{0}$ be any value of $t$ such that $f(x, y)=t_{0}$ does not contain any critical points or arcs. Then there will exist a small neighborhood, $\left|t-t_{0}\right|<\delta$, such that for any $t$ in this neighborhood $f(x, y)=t$ does not contain any critical points or arcs. Let

$$
\xi=f(x, y) \quad \text { and } \quad \eta=\Psi(x, y) \text {, }
$$

where $Y(x, y)=$ const. is the family of orthogonal trajectories to the family of curves $f(x, y)=t$. Since $f(x, y)$ is analytic in and on the boundary of $D, f(x, y)$ is analytic in a small neighborhood of each boundary point of $D$. Hence the orthogonal trajectcries $\Psi(x, y)$ are defined even for $(x, y)$ outsi de of but sufficiently near D. The transformation from $(x, y)$ to $(\xi, \eta)$ is analytic, one-to-one, and its inverse is also analytic.

Let us call $D_{1}$ the subdomain of $D$ containing all $(x, y)$ for which $f(x, y)=t$, where $\left|t-t_{0}\right|<\delta$. We may therefore write, in view of $(8)$,

$$
h_{1}(t)=\iint_{D_{1}} G(\xi, \eta) \delta(t-\xi) \frac{\partial(x, y)}{\partial(\xi, \eta)} d \xi d \eta
$$

or

$$
h_{1}(t)=\int_{\eta_{1}(t)}^{\eta_{2}(t)} G(t, \eta) \frac{\partial(x, y)}{\partial(t, \eta)} d \eta \text {. }
$$

If the contour line $f(x, y)=t_{0}$ is a closed curve (see Fig. la) then the $(\xi, \eta)$-subdomain corresponding to the subdomain $f(x, y)=t$ with $\left|t-t_{0}\right|<\delta$ will 
Now let $t_{0}$ be a value of $t$ such that there is a critical point $\left(x_{0}, y_{0}\right)$ on the contour line $f(x, y)=t_{0}$ (see Fig. 2). Let us again consider a small interval of $t$-values, $\left|t-t_{0}\right|<\delta$. We shall isolate this critical point $\left(x_{0}, y_{0}\right)$ by one or more arcs such that for any value of $t$ in this interval $f(x, y)=t$ will be decomposed into two parts, one lying within a neighbornood of $\left(x_{0}, y_{0}\right)$ bounded by these $\operatorname{arcs}$ and another lying outside. We require that these arcs be analytic*. Then $h(t)$ will consist of two integrals, one of the form (18) which will be analytic and another, $h_{0}(t)$, given bv some integral of the form ( 8 ) but extending only over those $(x, y)$-values lying within the region bounded by the arcs isolating $\left(\mathrm{x}_{0}, \mathrm{y}_{0}\right)$.

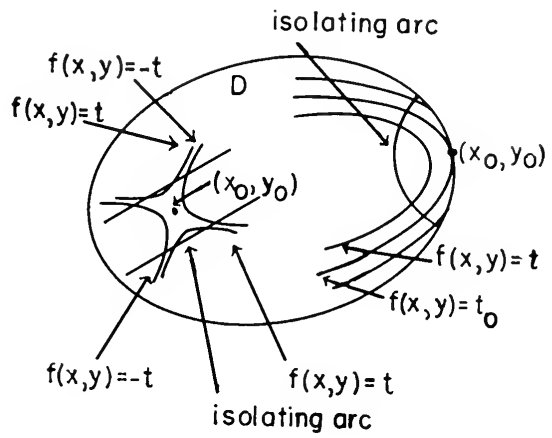
We shall see later that $h_{0}(t)$ is non-analytic for $t=t_{0}$. Woreover, it follows that the non-analytic form of $h_{0}(t)$ is independent of the choice of the arcs isolating $\left(x_{0}, y_{0}\right)$ provided only that they be analytic.

We have therefore shown that the values of $t$ at which $h(t)$ is not analytic are limited to those values of $t$ for which $f(x, y)=t$ contains one or more critical points $(x, y)$. Further, if $t_{0}$ is indeed a value of $t$ at which $h(t)$ is not analytic, then the non-analytic part of $h(t)$ in the neighborhood of $t=t_{0}$ is determined by an arbitrarily small neighborhood in $D$ of the critical point $(x, y)$ which lies on $f(x, y)=t_{0}$

The prectse choice of the shapes of these arcs will be specified in considering the various types of critical points. We need to be careful later only to observe the analyticity condition to be imposed on these arcs. The deoomposition of the path $f(x, y)=t$ into two parts will be needed to treat only some of the critical points to be considered later. 
4. Contributions from critical, non-stationary boundary points

Let us use the term non-stationary point for points $(x, y)$ at which at least one of the partial derivatives $f_{x}$ and $f_{y}$ is not zero. We have just seen that a non-stationary point $\left(\mathrm{x}_{0}, \mathrm{y}_{0}\right)$ is ordinary if it is an interior point of $\mathrm{D}$ or if it is a boundary point for which the contour line $f(x, y)=$ const. through it intersects the boundary and if the boundary is analytic at the intersection. There may, however, by non-stationary boundary points which are critical.

4.I We consider a non-stationary boundary point $\left(\mathrm{x}_{0}, \mathrm{y}_{0}\right)$ such that the boundary is analytic at $\left(x_{0}, y_{0}\right)$ and such that the contour line $f(x, y)=t_{0}$ through $\left(x_{0}, y_{0}\right)$ is tangent to the boundary. Let us suppose that $f_{x}\left(x_{0}, y_{0}\right) \neq 0$ and that the equation of the boundary curve is $\phi(x, y)=($. We shall first show how to choose new coordinates $X, Y$ such that for the transform $F(X, Y)$ of $f(x, y), F_{10}$ or aF/aX at $\left(X_{0}, Y_{0}\right) \neq 0, F_{O I}\left(X_{0}, Y_{0}\right)=0$, the boundary $\phi(x, y)=0$ becomes the $X=0$ axis, and the positive direction of the X-axis points into $D_{\text {. }}$

Since the contour line $f(x, y)=t_{0}$ is tangent to the boundary at $\left(x_{0}, y_{0}\right)$ we have at $\left(\mathrm{x}_{0}, \mathrm{y}_{0}\right)$

$$
\left|\begin{array}{ll}
f_{x} & f_{y} \\
\phi_{x} & \phi_{y}
\end{array}\right|=0
$$

We make the linear transformation *

$$
\begin{aligned}
& x-x_{0}=a u-m \phi_{y} v \\
& y-y_{0}=c u+m \phi_{x} v
\end{aligned}, \quad\left|\begin{array}{cc}
a & -m \phi_{y} \\
c & m \phi_{x}
\end{array}\right|=1,
$$

with the choice of $a$ and $c$ such as to make the positive u-axis point into $D$. Since

$$
f(x, y)=f_{00}+f_{10}\left(x-x_{0}\right)+f_{01}\left(y-y_{0}\right)+f_{20}\left(x-x_{0} ;^{2}+f_{11}\left(x-x_{0}\right)\left(y-y_{0}\right)+\ldots,\right.
$$

This transformation is suggested by Focke[6], p. 38 . 
then, if $\overline{\mathrm{f}}(\mathrm{u}, \mathrm{v})$ denotes the transform of $f(x, y)$,

$$
\bar{I}(u, v)=\overline{\mathrm{I}}_{00}+\overline{\mathrm{I}}_{10} u+\overline{\mathrm{f}}_{20} u^{2}+\overline{\mathrm{I}}_{11} u v+\cdots \cdot
$$

Morecuer

$$
\bar{\varnothing}(\mathrm{u}, \mathrm{v})=\bar{\varnothing}_{10} \mathrm{u}+\bar{\phi}_{20} \mathrm{u}^{2}+\bar{\phi}_{11} u \mathrm{v}+\cdots \cdot
$$

To make the boundary curve of $D$ the $X=0$ axis, we introduce $X, Y$ through

$$
\begin{aligned}
\bar{\emptyset}_{10} \mathrm{X} & =\bar{\varnothing}_{10} \mathrm{u}+\bar{\varnothing}_{20} \mathrm{u}^{2}+\bar{\varnothing}_{11} \mathrm{uv}+\ldots \\
\mathrm{Y} & =\mathrm{v} .
\end{aligned}
$$

We invert these equations to obtain $u$ and $v$ and substitute in (19). Then

$$
F(X, Y)=F_{00}+F_{10} X+F_{20} X^{2}+F_{11} X Y+F_{02} Y^{2}+\cdots, \quad F_{10} \neq 0 .
$$

Let us suprose first that $\mathrm{F}_{10}>0$ and $\mathrm{F}_{\mathrm{O} 2}>0$.

We shall now use formula (14) to calculate $h_{0}(t)$ in the neighborhood of $X=0, Y=0$. However where we formerly decomposed $F(X, Y)$ into $F_{0}+F_{1}$, we shall find it more convenient in the future to write

$$
F(X, Y)=F_{O O}+F_{O}+F_{I}
$$

and let $\xi$ in (9) be the new $F_{0}$. This means merely that we must replace $t$ in (14) by $t-\mathrm{F}_{00^{\circ}}$ With this new understanding as to the meaning of $\xi$, let us choose

$$
\xi=F_{10} x+F_{02} Y^{2} ;
$$

then the transformation (9) from $X, Y$ to $\xi, \eta$ is defined by

$$
X=\frac{\xi \cos ^{2} \eta}{F_{10}}, \quad Y=\frac{\xi^{1 / 2} \sin \eta}{\left(F_{02}\right)^{1 / 2}}
$$

Ve now use (15) and (14) to obtain for $t>\mathrm{F}_{00}$

* It follows from $(20)$ that $\partial u / \partial Y=0$ at $u=0, v=0$. See, for example, Courant, [II]. ** We suppose here that $F_{02}(0,0) \neq 0$. This means that the curvature of the contour Line through $(0,0)$, the line for which $F(X, Y)=t_{0}=F_{0 O}$, does not coincide with the curvature of the boundary at the point $(0,0)$. The case of $F_{02}=0$ could be treated by the method of the next section. 
(22)

$$
\begin{aligned}
h_{0}\left(t-F_{00}\right)=\sum_{r=0}^{\infty} \frac{\partial^{r}}{\partial t^{r}} \int_{-\frac{\pi}{c}}^{\frac{\pi}{2}} \frac{\left(t-F_{00}\right)^{1 / 2}}{F_{10} F_{02}^{1 / 2}} \cos \eta \sum_{\lambda=0}^{\infty} \sum_{\mu=0}^{\infty} \frac{\left(t-F_{00}\right)^{\lambda+\mu / 2}}{F_{10}^{\lambda} F_{02}^{\mu / 2}} \\
\cdot \cos ^{2 \lambda} \eta \sin ^{\mu} \eta \sum_{p=0}^{\lambda} \sum_{q=0}^{\mu} G_{\lambda-p, \mu-q} F_{r, p, q} d \eta .
\end{aligned}
$$

For $t<F_{\infty}$ there are no contour

lines in $D_{0}$ and therefore

$h_{0}\left(t-F_{\infty}\right)=0$ (see Fig. 3).

The integral in (22)

vanishes unless $\mu$ is even.

Also $F_{r, p, q}$ is zero if

$2 p+q<3 r$ in view of

the choice of $\xi$ in (2I).

Hence

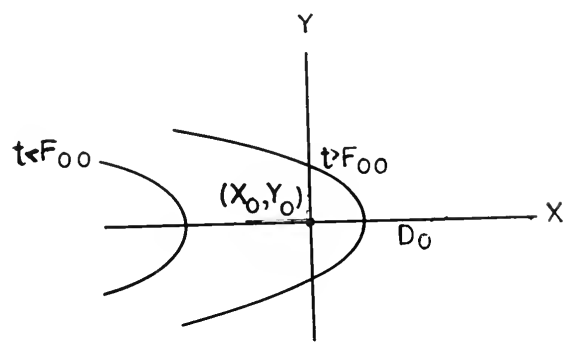

Fig. 3

$$
\begin{aligned}
h_{0}\left(t-F_{\infty 0}\right)= & \sum_{m=0}^{\infty} \sum_{r=0}^{2 m} \frac{\left(t-F_{00}\right)^{m+1 / 2}}{(m+1 / 2) !} \sum_{\lambda=0}^{m+r} \frac{(m+r-\lambda-1 / 2) ! \lambda !}{F_{10}^{\lambda+1} F_{02} m+r-\lambda+1 / 2} \\
& \cdot \sum_{p=0}^{\lambda} \sum_{q=0}^{2(m+r-\lambda)} G_{\lambda-p, 2 m+2 r-2 \lambda-q} F_{r, p, q} .
\end{aligned}
$$

The application of Erdélyi's theorem now shows that the contribution of this critical value $F_{00}$ of $t$ to the asymptotic expansion of $J$ is

$$
\sum_{m=0}^{\infty} \frac{e^{i k F_{00}+\frac{i \pi}{2}\left(m+\frac{3}{2}\right)}}{k^{m+3 / 2}\left|F_{02}\right|^{1 / 2}} \sum_{r=0}^{2 m} \sum_{\lambda=0}^{m+r} \frac{\lambda l\left(m+r-\lambda-\frac{1}{2}\right) !}{F_{10}^{\lambda+1} F_{02}^{m+r-\lambda}} \sum_{p=0}^{\lambda} \sum_{q=0}^{2(m+r-\lambda)} G_{\lambda-p, 2 m+2 r-2 \lambda-q^{F} r, p, q^{*}}
$$

We have put $\left|\mathrm{F}_{02}\right|^{1 / 2}$ in (24) because it will be seen shortly that (24) is then applicable to other casos with small modification. 
We now consider the case where $\mathrm{F}_{10}<0$ and $\mathrm{F}_{\mathrm{O} 2}>0$ (Fig. 4). The domain $\mathrm{D}_{0}$ lies to the right of $Y=0$. We can, however, consider a domain $D_{0}^{1}$ which surrounds the point $X_{0}$, $Y_{0}, \theta \cdot g \cdot$, the domain ABCDE. In this domain $h_{0}(t)$ is analytic for all $t$ near $t_{0}$ because at lease one of $f_{x}$ and $f_{y}$ is not zero at $\left(x_{0}, y_{0}\right)$ and $\left(x_{0}, y_{0}\right)$ is an interior

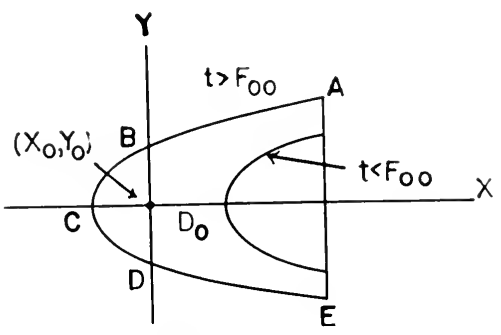

Fig. 4 point of $D_{0}^{\prime}$. Then the $h_{0}(t)$ which corresponds to the path in $D_{0}$ itself is the difference of an analytic function and the value of $h_{0}(t)$ for the path $l y i n g$ in $\mathrm{BCD}$. But the domain BCD occupies the same position with respect to the axis $X=0$ as the case already treated. Hence the final result is the same as $(24)$. When $\mathrm{F}_{10}>0$ and $\mathrm{F}_{02}<0$, the part of $\mathrm{h}_{0}(t)$ which contributes to the asymptotic expansion is zero for $t>F_{00}$ but, for $t<F_{00}$, (23) is alterec by having $\left(t-F_{0 O}\right)^{m+1 / 2}$ and $F_{02}^{I / 2}$ replaced by $-(-I)^{m}\left(F_{00}-t\right)^{m+1 / 2}$ and $\left(-F_{02}\right)^{I / 2}$ respectively. Thus (24) is unchanged apart from $e^{i \pi(m+3 / 2) / 2}$ being replaced by $e^{i \pi(m+1 / 2) / 2}$. The same result holds for $\mathrm{F}_{10}<0$ and $\mathrm{F}_{02}<0$.

4.2 We consider next the type of critical non-stationary boundary point $\left(\mathrm{x}_{0}, \mathrm{y}_{0}\right)$ such that the contour line through $\left(\mathrm{x}_{0}, \mathrm{y}_{0}\right)$ coincides with the boundary over a finite length (see Fig. 5). The coordinates $X$ and $Y$ are chosen as in the case of 4.1. However because the contour line and boundary will possess the same curvature at $\left(\mathrm{X}_{0}, \mathrm{Y}_{0}\right)$ we have

$$
F(X, Y)=F_{00}+F_{10} X+F_{20} X^{2}+F_{11} X Y+F_{30} X^{3}+\ldots, \quad F_{10} \neq 0 .
$$

We choose $\xi$ and $\eta$ thus:

$$
\xi=F_{10} X, \quad \eta=Y
$$


and consider first the case $F_{10}>0$. Then $h_{0}(t)=0$ for $t<F_{00}$. For $t>0$, we use (15) and (14) to obtain

$$
h\left(t-F_{00}\right)=\sum_{r=0}^{\infty} \frac{\partial^{r}}{\partial t^{r}} \int_{a}^{b} \sum_{\lambda=0}^{\infty} \sum_{\mu=0}^{\infty} \frac{\left(t-F_{00}\right)^{\lambda}}{F_{10}^{\lambda+1}} \eta^{\mu} \sum_{p=0}^{\lambda} \sum_{q=0}^{\mu} G_{\lambda-p, \mu-q} F_{r, p} d \eta .
$$

Consequently there is a contribution

to the asymptotic expansion of $\mathrm{J}$,

which because $h\left(t-F_{00}\right)$ possesser con-

tinuous derivatives of all orders,

will consist of the zeroth and posi-

tive integral powers of $1 / k$. However

the coefficients of this expansion

Fig. 5

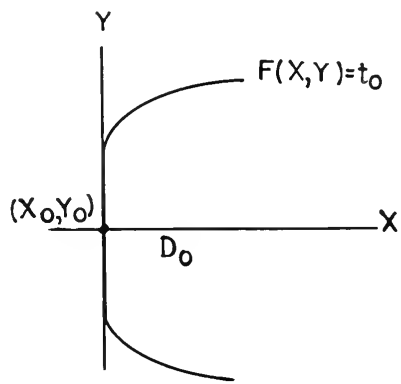

will depend upon the length of are over which the boundary of $D$ and the contour line $f(x, y)=t_{0}$ coincide. They will therefore not be given explicitly.

4.3 We consider next the contribution of a corner in the boundary of $D$ to the asymptotic expansion of J. More precisely state, we consider a point $\left(\mathrm{x}_{0}, \mathrm{y}_{0}\right)$ on the boundary of $\mathrm{D}$ at which the direction of the tangente to the boundary changes discontinuously but such that the direction of the tangent to the contour line $f(x, y)=t_{0}$ through $\left(x_{0}, y_{0}\right)$ does not coincide with tither the right or left-hand directione of the tangents to $D$ at $\left(x_{0}, y_{0}\right)$.

We shall determine a change of variables from $(x, y)$ to $(X, Y)$ so that the boundary of $D$ at $\left(x_{0}, y_{0}\right)$ will fall along the upper half of the $Y$-axis and along the right half of the $X$-axis, so that the domain $D_{0}$ will consist of the region $X \geq 0, I \geq 0$ near $X_{0}=0, Y_{0}=0$.

Let the boundary arcs on either side of $\left(x_{0}, y_{0}\right)$ be given respectively by $\phi(x, y)=0$ and $Y(x, y)=0$. Moreover, since the tangent to $D$ at $\left(x_{0}, y_{0}\right)$ changes diecontinuously, we have at $\left(x_{0}, y_{0}\right)$ 


$$
\left|\begin{array}{ll}
\phi_{x} & \phi_{y} \\
y_{x} & y_{y}
\end{array}\right| \neq 0
$$

Since we presuppose that the tangent to the contour line $f(x, y)=t_{0}$ does not coincide with either of the above tangents, we have also

$$
\left|\begin{array}{ll}
q_{x} & g_{y} \\
f_{x} & f_{y}
\end{array}\right| \neq 0 \quad \text { and } \quad\left|\begin{array}{ll}
y_{x} & y_{y} \\
f_{x} & f_{y}
\end{array}\right| \neq 0
$$

We consider the linear transformation

$$
\begin{aligned}
& x-x_{0}=a u+b \nabla \\
& y-y_{0}=c u+d \nabla,
\end{aligned}\left|\begin{array}{ll}
a & b \\
c & d
\end{array}\right|=1,
$$

and choose $a, b, c, d$ to satisfy the conditions

$$
\begin{aligned}
& a I_{x}+c I_{y}=0 \\
& b \varphi_{x}+d \phi_{y}=0
\end{aligned}
$$

and make the positive $u$-axis and positive v-axis lie along the tangents to $D$ at $\left(x_{0}, y_{0}\right)$. In terms of $u$ and $v$, then, the expansions of $\phi(x, y)$ and $\Psi(x, y)$ are

$$
\begin{aligned}
& \bar{\phi}(u, v)=\bar{\phi}_{10} u+\bar{\phi}_{20} u^{2}+\bar{\phi}_{11} u v+\bar{\phi}_{02} v^{2}+\ldots \\
& \bar{Y}(u, v)=\bar{I}_{01} v+\bar{\Phi}_{20} u^{2}+\bar{\nabla}_{11} u v+\bar{y}_{02} v^{2}+\ldots
\end{aligned}
$$

and

$$
\bar{f}(u, v)=\bar{f}_{00}+\bar{f}_{10} u+\bar{f}_{01} v+\bar{f}_{20} u^{2}+\ldots
$$

wherein $\bar{f}_{10} \neq 0$ and $\bar{f}_{01} \neq 0$ becsuse of $(26)$.

To make the boundary ares of $n$ near $\left(x_{0}, y_{0}\right)$ coincide with the $X$-and Y-axes

wo let

$$
\begin{aligned}
& \bar{\nabla}_{10} \mathrm{x}-\bar{\nabla}_{10} u+\bar{\phi}_{20} u^{2}+\cdots \\
& \mathbf{Y}_{\mathrm{OI}} \mathbf{Y}-\mathbf{Y}_{\mathrm{OI}} \mathbf{\nabla}+\mathbf{Y}_{2 \mathrm{O}} \mathrm{u}^{2}+\cdots \cdot
\end{aligned}
$$


We invert this transformation and substitute in (27). Then

$$
F(X, Y)=F_{00}+F_{10} X+F_{01} Y+\ldots, \quad F_{10} \neq 0, F_{01} \neq 0 .
$$

Let

$$
\xi=F_{10} X+F_{01} Y .
$$

Suppose that $\mathrm{F}_{10}>0$ and $\mathrm{F}_{\mathrm{CI}}>0$. Then the faths of integration are shown in Fig. 6. Accordingly we make the transformation

$$
X=\frac{\xi}{F_{10}} \cos ^{2} \eta, \quad Y=\frac{\xi}{F_{01}} \sin ^{2} \eta .
$$

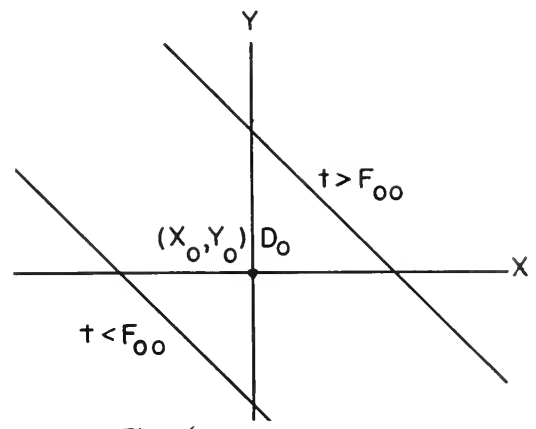

Fig. 6

Now $h_{0}(t)=0$ for $t<F_{00}$ because the contour lines $f(x, y)=t$ lie outside of $n_{0}$. For $t>F_{00}$ we use equations (17) and (14) to obtain

$$
h_{0}\left(t-F_{00}\right)=\sum_{r=0}^{\infty} \frac{\partial^{r}}{\partial t^{r}} \int_{0}^{\frac{\pi}{c}} \frac{2\left(t-F_{C 0}\right)}{F_{10} F_{01}} \sum_{\mu=0}^{\infty}\left(t-F_{00}\right)^{\mu} \sum_{\lambda=0}^{\mu} \frac{\cos ^{2 \lambda+1} \eta \sin ^{2 \mu-2 \lambda+1} \eta}{F_{j 0}^{\lambda} F_{10}^{\mu-\lambda}}
$$

$$
\cdot \sum_{p=0}^{\lambda} \sum_{q=0}^{\mu-\lambda} G_{\lambda-p, \mu-\lambda-q} F_{r, p, q} d \eta \text {. }
$$

Since $F_{r, p, q}=0$ for $p+q<2 r$ we obtain

$$
\begin{aligned}
h_{0}\left(t-F_{00}\right)=\sum_{m=0}^{\infty} \sum_{r=0}^{m} \frac{\left(t-F_{00}\right)^{m+1}}{(m+1) !} & \sum_{\lambda=0}^{m+r} \frac{\lambda l(m+r-\lambda) !}{F_{10}^{\lambda+1} F_{01}^{m+r-\lambda+1}} \\
& \sum_{p=0}^{\lambda} \sum_{q=0}^{m+r-\lambda} G_{\lambda-p, m+r-\lambda-q} F_{r, p, q} .
\end{aligned}
$$

Hence the contribution of the point $\left(x_{0}, y_{0}\right)$ to the asymptotic expansicn of ( $I$ ) is

$$
\sum_{m=0}^{\infty} \frac{e^{1 k F} 00^{+\frac{i \pi}{2}(m+2)}}{k^{m+2}}-\sum_{r=0}^{m} \sum_{\lambda=0}^{m+r} \frac{\lambda !(m+r-\lambda) !}{F_{10}^{\lambda+1} F_{01}^{m+r-\lambda+1}} \sum_{p=0}^{\lambda} \sum_{q=0}^{m+r-\lambda} G_{\lambda-p, m+r-\lambda-q} F_{r, p, q} \cdot
$$


Whon $F_{10}<0$ and $F_{01}>0$, the behavior of the contour lines near $X_{0}-0$, $Y_{0}=0$ is shown in Fig. 7. The domain $D_{0}$ is still in the first quadrant surrounding $(0,0)$. Let us add to the domain $D_{0}$ the domain $D_{1}$ shown in the figure. Then the boundary of the domadn $D_{0}+D_{1}$ is the $X-a x i s$. This boundary is analytic and the contour lines cut the boundary. Hence $h\left(t-F_{00}\right)$ taken over $D_{0}+D_{1}$ is analytic for all $t$ near $t=F_{00}$. If we now subtract from this $h\left(t-F_{\infty}\right)$ the $h_{0}\left(t-F_{O O}\right)$ taken over the contour lines lying in $D_{1}$, we shall obtain the correct form of $h_{0}\left(t-F_{00}\right)$ for paths in $D_{0}$. The treatment of $h_{0}\left(t-F_{00}\right)$ in $D_{1}$ is precisely the same as that just given. Hence (28) and (29) obtain for this case tco. When $F_{10}<0$ and $F_{01}<0$ the paths $t \geqslant F_{00}$ as given in Fig. 6 are interchanged. Hence (29) gives the result for this case too. Likewise the case $F_{10}>0$ and $F_{01}<0$ yields the result (29).

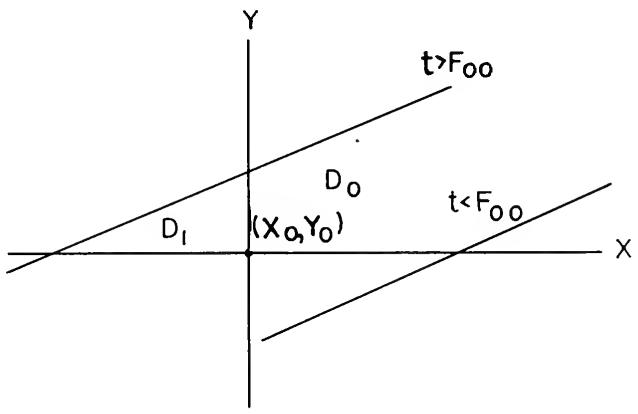

Fig. 7

4.4 We consider as the final case of a critical non-stationary boundary point an $\left(x_{0}, y_{0}\right)$ where the direction of the tangent to the boundary of $D$ changes discontinuously and one part of the boundary coincides with the contour line $f(x, y)=$ const. through $\left(x_{0}, y_{0}\right)$. As in the case treated in $(4.2)$ we shall obtain a series of powers of $\frac{1}{\mathrm{k}}$ whose coefficients depend upon the domain of integration and will therefore not be given. 
$-22-$

5. Contributions from interior stationary points

We consider next interior points of $D$ at which both $f_{x}$ and $f_{y}$ are zero.

5.1 Let the point $\left(x_{0}, y_{0}\right)$ be a relative minimum or maximum of $f(x, y)$. By a simple rotation of coordinates we may write

$$
F(X, Y)=F_{O 0}+F_{20}\left(X-X_{0}\right)^{2}+F_{O 2}\left(Y-Y_{0}\right)^{2}+\cdots \cdot
$$

In a small neighborhood $D_{0}$ of $\left(X_{0}, Y_{0}\right)$ the contour lines $F$ cont. are closed curves surrounding $\left(X_{0}, Y_{0}\right)$ (see Fig. 8). We shall use (17) and (14) to calculate $h_{0}(t)$ in $D_{0^{\circ}}$. Suppose, firstly, that $F_{20}>0$ and $F_{02}>0$. Then let

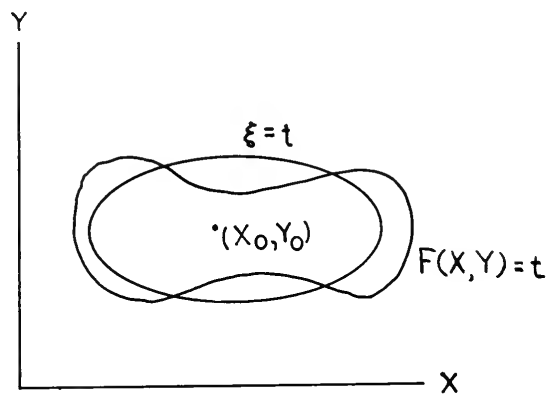

Fig. 8

$$
X-X_{0}=\xi^{1 / 2} \frac{\cos \eta}{F_{20}^{1 / 2}}, \quad Y-Y_{0}=\xi^{1 / 2} \frac{\sin \eta}{\frac{1 / 2}{F_{02}}} \text {, }
$$

so that

$$
\xi=F_{20}\left(X-X_{0}\right)^{2}+F_{02}\left(Y-Y_{0}\right)^{2}
$$

Now $h\left(t-F_{00}\right)=0$ for $t<F_{00^{\circ}}$ By $(17)$ and $(14)$ we obtain for $t>F_{00}$

(32)

$$
\begin{aligned}
h_{0}\left(t-F_{00}\right)= & \sum_{r=0}^{\infty} \frac{\delta}{\partial t^{r}} \int_{0}^{2 \pi} \frac{1}{2\left(F_{20} F_{02}\right)^{1 / 2}} \sum_{\mu=0}^{\infty} \sum_{\lambda=0}^{\mu}\left(t-F_{00}\right)^{\mu / 2} \frac{\cos ^{\lambda} \eta \sin ^{\mu-\lambda} \eta}{F_{20}^{\lambda / 2} F_{02}^{\mu-\lambda / 2}} \\
& \cdot \sum_{p=0}^{\lambda} \sum_{q=0}^{\mu-\lambda} G_{\lambda-p, \mu-\lambda-q} F_{r, p, q} d r_{i} .
\end{aligned}
$$


The integral vanishes except when $\lambda$ and $\mu-\lambda$ are even. Furthermore, in vi ew of the choice of $\xi$ in $(31), F_{r, p, q}=0$ for $p+q<3 r$. Hence for $t>F_{\text {on }}$

$$
\begin{aligned}
& h_{0}\left(t-F_{\infty 0}\right)=\frac{1}{\left(F_{20} F_{O 2}\right)^{1 / c}} \sum_{m=0}^{\infty} \sum_{r=0}^{2 m} \frac{\left(t-F_{00}\right)^{m}}{m !} \sum_{\lambda=0}^{m+r} \frac{\left(\lambda-\frac{1}{2}\right) !\left(m+r-\lambda-\frac{1}{2}\right) !}{F_{20}^{\lambda}} \frac{F_{02}^{m+r-\lambda}}{2} \\
& \cdot \sum_{p=0}^{i \lambda} \sum_{q=0}^{2 r+2 m-2 \lambda}{ }_{2 \lambda-p, 2 r+2 m-2 \lambda-q} F_{r, p, q} \cdot
\end{aligned}
$$

Consequently, by Frdelyi's theorem, the contribution of this critical point to the asymptotic expansion of $\mathrm{J}$ is

(34)

$$
\frac{e^{i k F_{00}}}{\left|F_{20} F_{02}\right|^{1 / 2}} \sum_{m=0}^{\infty} \frac{e^{i \frac{\pi}{2}(m+1)}}{k^{m+1}} \sum_{r=0}^{2 m} \sum_{\lambda=0}^{m+r} \frac{\left(\lambda-\frac{1}{2}\right) !\left(m+r-\lambda-\frac{1}{2}\right) !}{F_{20}^{\lambda} F_{02}^{m+r-\lambda}}
$$

$$
\text { - } \sum_{p=0}^{2 \lambda} \sum_{q=0}^{2 r+2 m-2 \lambda} G_{2 \lambda-p, 2 r+2 m-2 \lambda-q} F_{r, p, q}
$$

The modulus of $\mathrm{F}_{20} \mathrm{~F}_{\mathrm{O} 2}$ has been introduced to facilitate comparison with other cas s.

When $\mathrm{F}_{20}<0$ and $\mathrm{F}_{\mathrm{OC}}<0$, the result is the same as (33) except that $t>\mathrm{F}_{0 O}$ and $\mathrm{t}<\mathrm{F}_{\mathrm{CO}}$ are interchariged. Hence we obtain (34) with the sign reversed.

5. 2 Let the point $\left(x_{0}, y_{0}\right)$ be a saddle point of $f(x, y)$, so that $f_{x x} f_{y y}-f_{x y}^{2}<0$. The coordinates $X, Y$ are chosen so that (30) holds. We assume, firstly, that

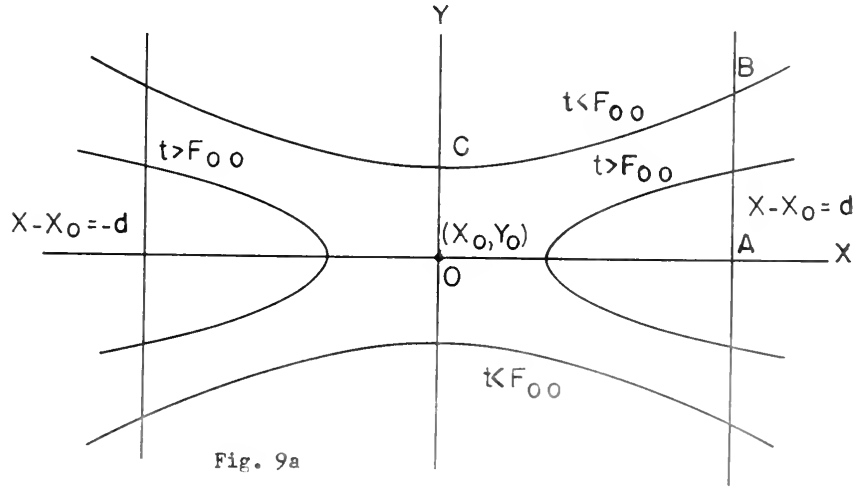


$F_{20}>0$ and $F_{02}<0$. Then we shall evaluate $h_{0}(t)$ between $X-X_{0}=-d$ and $X-X_{0}=d(s e \theta$ Fig. 9a). The path of integration is given by

$$
\xi=F_{20}\left(X-X_{0}\right)^{2}+F_{02}\left(Y-Y_{0}\right)^{2},
$$

so that the $t$ interval $\left|t-t_{0}\right|<\delta$ is covered by the family of hyperbolas corresponding to $\xi>0, \xi=0$, and $\xi<0$. Let $\eta=X-x_{0}$. We note that for a given $t$, the hyperbola $\xi=t-F_{O O}$ is symmetric with respect to the $X$ and $Y$ axes. Hence we shall see in a moment that we need consider only that part of the path which lies in the first quadrant to evaluate (14).

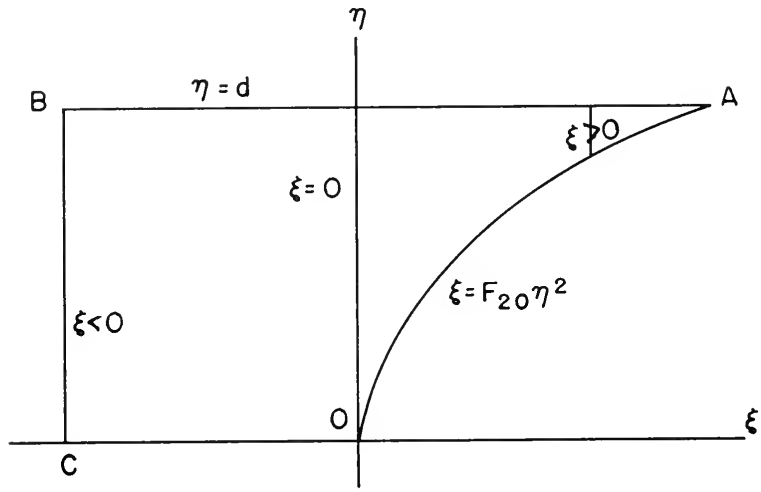

Fig. 9b

Using the notation of article 2, let us consider the integral

$$
\iint_{D_{0}} \frac{(-1)^{r}}{r !} G(X, Y) F_{I}^{r}(X, Y) \delta\left(t-F_{0}\right) d X d Y .
$$

If we transform from $X, Y$ to $\xi, \eta$ in accordance with (9) and write the resulting double integral as a repeated integral with respect to $\eta$ and then $\xi$ we obtain

$$
\int_{\xi_{1}}^{\xi_{2}} \delta(t-\xi) \int_{\eta_{1}(\xi)}^{\eta_{2}(\xi)} \frac{(-1)^{r}}{r !} \hbar(\xi, \eta) \eta_{1}^{r}(\xi, \eta) \frac{\partial(x, y)}{\partial(\xi, \eta)} d \eta d \xi .
$$

Iet $K(\xi)$ denote the inner integral. Then this double intogral becomes 


$$
\int_{\xi_{1}}^{\xi} \varepsilon(t-\xi) K(\xi) d \xi
$$

or

$$
K(t)
$$

which 18

$$
\int_{\eta_{1}(t)}^{\eta_{2}(t)} \frac{(-1)^{r}}{r !} y(t, \eta) j_{1}^{r}(t, \eta) \frac{\partial(x, y)}{\partial(t, \eta)} d \eta .
$$

We see therefore that each term of (14) can be regarded as coming from a term such as (35). If however evaluate (35) over a path symmetrical with respect to both the X- and Y-axes, such as an hyperbola of Fig. 9a, and if we use the expansion (15) for the first three factors of the integrand, then we need retain only those terms in the expansion which contain even powers of both $X-X_{0}$ and $Y-Y_{0}$. Moreover, for these terms the integral (14) is four times the integral taken over the path in the $(\xi, \eta)$ plane (see FIg. 9b) corresponding to that part of the hyperbola which $11 e s$ in the first quadrant. Hence we obtain for (14)

$$
\left.h_{0}\left(t-F_{00}\right)=-4 \sum_{r=0}^{\infty} \frac{\partial^{r}}{\partial t^{r}} \int_{/ t-F_{00}}^{d}\right)^{1 / 2} \sum_{20} \sum_{\lambda=0}^{\infty} \sum_{\mu=0}^{\infty} \eta^{2 \lambda} \frac{\left(F_{20} \eta^{2}-t+F_{00}\right)^{\mu-1 / 2}}{2 F_{02}\left(-F_{02}\right)^{\mu-1 / 2}}
$$

$$
\cdot \sum_{p=0}^{2 \lambda} \sum_{q=0}^{2 \mu} G_{2 \lambda-p, 2 \mu-q} F_{r, p, q} d \eta \text {. }
$$

We consider therefore integrals of the form

\footnotetext{
* In the domain of Fig. 9a, Y - Y is positive in the first quadrant and hence we write

$$
Y-Y_{0}=\sqrt{\frac{F_{20} \eta^{2}-\xi}{-F_{02}}} \text {. }
$$
}




$$
I_{m, n}=\int_{T^{1 / 2} H(T) / F_{20}^{I / 2}}^{d} \eta^{2 m}\left(F_{20} \eta^{2}-T\right)^{n-1 / 2} d \eta
$$

where $T=t-F_{00}$, and $H(T)$ is the Heaviside unit function, i.e., $H(T)=0$ for $T<0$ and $H(T)=1$ for $T>0$.

By integration,

$$
I_{m, n}=\frac{d^{2 m+1}\left(F_{20} d^{2}-T\right)^{n-1 / 2}}{2 m+2 n}-\frac{2 n-1}{2 m+2 n} T I_{m, n-1} \text { for } n \geq 1 .
$$

At $t=F_{00}$, that is, at $T=0$, the first term is continuous and has continuous derivatives of all orders. Hence it may be neglected because it will not contribute to the asymptotic expansion of $\mathrm{J}$. Continuing the integration we obtain

$$
I_{m, n}=\frac{(-1)^{n}(2 n-1)(2 n-3) \ldots 1}{(c m+2 n)(2 m+2 n-2) \ldots(2 m+2)} T^{n} I_{m, 0} .
$$

Further,

$$
I_{m, 0}=\frac{d^{2 m-I}\left(F_{20} d^{2}-T\right)^{1 / 2}}{2 m F_{20}}+\frac{2 m-I}{2 m} \frac{T}{F_{20}} I_{m-1,0} \text { for } m \geq 1
$$

Once again the first term may be neglected insofar as contribution to the asymptotic expansion is concerned, so that

$$
I_{m, 0}=\frac{(2 m-1)(2 m-3) \ldots I}{2 m(2 m-2) \ldots 2} \frac{T^{m}}{F_{20}^{m}} I_{0,0} .
$$

Since

$$
I_{0,0}=\frac{1}{F_{20}^{1 / 2}} \log \frac{d+\left(d^{2}-T / F 20\right)^{I / 2}}{|T|^{1 / 2} F_{20}^{1 / \hat{L}}}
$$

and since the numerator in the logarithmic factor will not contribute to the asymptotic expansion, the significant part of $I_{m, n}$ is given by 


$$
I_{m, n}=(-1)^{n+1} \frac{(m-1 / 2) !(n-1 / 2) !}{(m+n) 12 \pi F_{20}^{m+1} \frac{72}{m+n}} T^{m}|T|
$$

Therefore the relevant fart of $h_{0}\left(t-F_{O C}\right)$ is

$$
\begin{gathered}
4 \sum_{r=0}^{\infty} \frac{\partial^{r}}{\partial t^{r}} \sum_{\lambda=0}^{\infty} \sum_{\mu=0}^{\infty}(-1)^{\mu} \frac{\left(\lambda-\frac{1}{2}\right) !\left(\mu-\frac{1}{2}\right) !}{2 F_{02}\left(-F_{02}\right)^{\mu-1 / 2}(\lambda+\mu) ! 2 \pi F_{20}^{\lambda+1 / 2}}\left(t-F_{00}\right)^{\lambda+\mu} \\
\cdot \log \left|t-F_{C O}\right| \sum_{p=0}^{2 \lambda} \sum_{q=0}^{2 \mu} G_{2 \lambda-p, 2 \mu-q} F_{r, p, q}
\end{gathered}
$$

Since we can ignore continuous functions with continuous derivatives we can replace

$$
\frac{\partial^{r}}{\partial t^{r}}\left(t-F_{0 O}\right)^{\lambda+\mu} \log \left|t-F_{C O}\right|
$$

by

$$
\frac{(\lambda+\mu) !}{(\lambda+\mu-r) !}\left(t-F_{C O}\right)^{\lambda+\mu-r} \log \left|t-F_{0 O}\right|
$$

Also, $F_{r, p, q}=0$ if $p+q<3 r$, so that the significant part of $h_{0}\left(t-F_{O O}\right)$ is

$$
\frac{1}{\left(-F_{20} F_{02}\right)^{1 / 2}} \sum_{m=0}^{\infty} \sum_{r=0}^{2 m} \frac{\left(t-F_{00}\right)^{m}}{m ! r} \log \left|t-F_{00}\right| \sum_{\lambda=0}^{m+r} \frac{\left(\lambda-\frac{1}{2}\right):\left(m+r-\lambda-\frac{1}{2}\right) !}{F_{20}^{\lambda} F_{02}^{m+r-\lambda}}
$$

$$
\cdot \sum_{p=0}^{2 \lambda} \sum_{q=0}^{2 r+2 m-2 \lambda} G_{2 \lambda-p, 2 r+2 m-2 \lambda-q} F_{r, p, q}
$$

Use of Theorem 4 of Appendix A now shows that the contribution to the asymptotic expansion of $J$ is the same as (34) multiplied by $i$.

This result remains unaltered if $\mathrm{F}_{20}<0$ and $\mathrm{F}_{02}>0$. 
5.3 Let the point $\left(x_{0}, y_{0}\right)$ be a double point, that is $f_{x x} f_{y y}-f_{x y}^{2}=0$. In this case we choose $X, Y$ so that ${ }^{*}$

$$
\begin{aligned}
F(X, Y)=F_{00}+F_{20}\left(X-X_{0}\right)^{2}+F_{30}\left(X-X_{0}\right)^{3} & +F_{21}\left(X-X_{0}\right)^{2}\left(Y-Y_{0}\right)+F_{12}\left(X-X_{0}\right)\left(Y-Y_{0}\right)^{2} \\
& +F_{03}\left(Y-Y_{0}\right)^{3}+\ldots, \quad F_{20} \neq 0 .
\end{aligned}
$$

We assume first that $\mathrm{F}_{20}>0$ and that $\mathrm{F}_{03}>0$, and choose

$$
\xi=F_{20}\left(X-X_{0}\right)^{2}+F_{03}\left(Y-Y_{0}\right)^{3}, \eta=X-X_{0} \cdot
$$

We shall evaluate $h_{0}(t)$ along $\xi=$ const. from $X-x_{0}=-d$ to $X-x_{0}=d$. For t-values from $t-F_{0 O}$ negative to $t-F_{\infty}$ positive, $\xi$ ranges from negative values to positive ones (see Fig. 10).

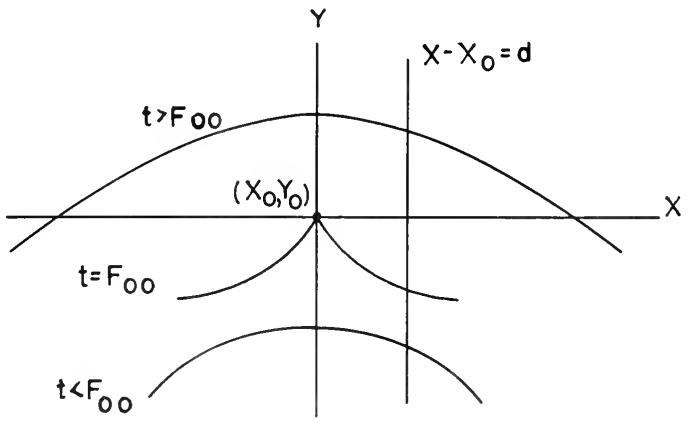

F1g. 10

* If $F_{12} \neq 0$ we can apply a further transformation, $X-X_{0}=\bar{X}-\bar{X}_{0}, Y-Y_{0}=\bar{Y}-\bar{Y}_{0}$ $-\frac{{ }^{F} 12}{3 F_{03}}\left(\bar{X}-\bar{X}_{0}\right)$, to ellminate the $F_{12}$ term. However this is not necessary in the cases considered here. 
However, the argument given in Section 5.2 concerning symetry of the pith of integration can be applied here. In this case we see from the symmetry of the domain of integration with respect to $Y=Y_{0}$ that we nee: retain only terms which involve even powers of $\mathrm{x}-\mathrm{x}_{0}$ in the expansion (15) ard multiply the result by 2. If we then make the change of variables from $X, Y$ to $\xi, \eta$ and use (14) we obtain

$$
\begin{aligned}
h_{0}\left(t-F_{00}\right)=2 & \sum_{r=0}^{\infty} \frac{\partial^{r}}{\partial t^{r}} \int_{0}^{d} \sum_{\lambda=0}^{\infty} \sum_{\mu=0}^{\infty} \frac{\eta^{2 \lambda}\left(T-F_{20} \eta^{2}\right)^{(\mu-2) / 3}}{3 F_{03} F_{03}(\mu-2) / 3} \\
& \cdot \sum_{p=0}^{2 \lambda} \sum_{q=0}^{\mu} c_{2 \lambda-p, 1-q} F_{r, p, q} d \eta,
\end{aligned}
$$

where, again, $\mathrm{T}=\mathrm{t}-\mathrm{F}_{00^{*}}$

We therefore have to evaluate integrals of the form

$$
J_{m, n}=\int_{0}^{d} \eta^{2 m}\left(T-F 20 \eta^{2}\right)^{(n-2) / 3} d \eta \text {. }
$$

Retaining only terms which contribute to the asymptotic expansion (cf. section 5.2), we find that

$$
\begin{aligned}
& J_{m, 3 s}=\frac{\left(m-\frac{1}{2}\right) !\left(\frac{n-2}{3}\right) !\left(-\frac{1}{6}\right) ! T^{m+s}}{\left(-\frac{1}{2}\right) !\left(-\frac{2}{3}\right) !\left(m+\frac{n}{3}-\frac{1}{6}\right) ! F_{20}^{m}} \int_{0}^{d}\left(T-F_{20} \eta^{2}\right)^{-2 / 3} d \eta ; \\
& J_{m, 3 s+1}=\frac{\left(m-\frac{1}{2}\right) !\left(\frac{n-2}{3}\right) !\left(\frac{1}{6}\right) ! T^{m+s}}{\left(-\frac{1}{2}\right) !\left(-\frac{1}{3}\right) !\left(m+\frac{n}{3}-\frac{1}{6}\right) ! F_{20}^{m}} \int_{0}^{d}\left(T-F_{20} \eta^{2}\right)^{-1 / 3} d \eta ; \\
& J_{m, 3 s+2}=0 .
\end{aligned}
$$

Now $d$ is independent of $\mathrm{T}$. Hence

$$
\int_{0}^{d}\left(T-F_{20} \eta^{2}\right)^{-2 / 3} d \eta=\int_{0}^{\infty}\left(T-F_{20} \eta^{2}\right)^{-2 / 3} d \eta
$$

aside from a term which is continuous and has continuous derivatives for values of $\mathrm{T}$ bounded away from 0 . We consider therefore the right-hand integral. 
For $\mathrm{T}>0$

$$
\int_{0}^{\infty}\left(T-F_{20} \eta^{2}\right)^{-2 / 3} d \eta=\int_{0}^{\left(T / F_{20}\right)^{1 / 2}}\left(T-F_{20} \eta^{2}\right)^{-2 / 3} d \eta+\int_{\left(T / F_{20}\right)^{1 / 2}}^{\infty}\left(T-F_{20} \eta^{2}\right)^{-2 / 3} d \eta .
$$

Make the substitution $\eta=\sqrt{\mathrm{T} / \mathrm{F}_{20}} \sin \theta$ in the first integral on the right and $\eta=\sqrt{\mathrm{T} / \mathrm{F}_{20}} \sec \theta$ in the second. Then ${ }^{*}$

$$
\begin{aligned}
\int_{0}^{\infty}\left(T-F_{20} \eta^{2}\right)^{-2 / 3} d \eta & =\frac{T^{-1 / 6}}{F_{20}^{1 / 2}} \int_{0}^{\frac{\pi}{2}}\left(\cos ^{-1 / 3} \theta+\sin ^{-1 / 3} \theta \cos ^{-2 / 3} \theta\right) d \theta \\
& =\frac{\left(-\frac{2}{3}\right) ! 3 \pi^{1 / 2} T^{-1 / 6}}{\left(-\frac{1}{6}\right) ! 2 F_{20}^{1 / 2}}
\end{aligned}
$$

For $\mathrm{T}<0$, we let $\eta=\sqrt{-\mathrm{T} / \mathrm{F}_{20}} \tan \theta$ to show that

$$
\int_{0}^{\infty}\left(T-F_{20} \eta^{2}\right)^{-2 / 3} d \eta=\frac{(-T)^{-1 / 6}}{F_{20}^{1 / 2}} \int_{0}^{\frac{\pi}{2}} \cos ^{-2 / 3} \theta d \theta=\frac{\left(-\frac{2}{3}\right) ! 3^{1 / 2} \pi^{1 / 2}}{\left(-\frac{1}{6}\right) ! 2 F_{20}^{1 / 2}}(-T)^{-1 / 6} .
$$

The integral for $\mathrm{J}_{\mathrm{m}, 3 \mathrm{~s}+1}$ may be dealt with in a similar way and we obtain

$$
\begin{aligned}
\int_{0}^{\mathrm{C}}\left(\mathrm{T}-\mathrm{F}_{20} \eta^{2}\right)^{-I / 3} d \eta & =\frac{\left(-\frac{1}{3}\right) ! 3 \pi^{1 / 2} T^{1 / 6}}{\left(\frac{1}{6}\right) ! 2 \mathrm{~F}_{20}^{1 / 2}} \text { for } \mathrm{T}>0 \\
& =\frac{\left(-\frac{1}{3}\right) ! 3^{1 / 2} \pi^{1 / 2}(-\mathrm{T})^{1 / 6}}{\left(\frac{1}{6}\right) ! 2 \mathrm{~F}_{20}^{1 / 2}} \text { for } \mathrm{T}<0,
\end{aligned}
$$

The first term in the integrand on the right may be integrated by a standard integral leading to Garma functions and the second by a standard integral involving Beta functions. The relationship $\Gamma(x) \Gamma(-x)=\frac{-\pi}{x \sin \pi x}$ may be used to transform intermediate result $\varepsilon$.

Before letting the upper limit become infinite we subtract the term $\left(-F_{20} \eta^{2}\right)^{-1 / 3}$ from the integrand. This term does not involve $T$ and hence does not contribute to the asymptotic expansion. However, it causes the integral with the infinite upper Limit to converge. 
- $31-$

apart from terms which do not contribute to the asymptotic expansion. Hence

$$
\begin{aligned}
J_{m, n} & =\frac{\left(m-\frac{1}{2}\right) !\left(\frac{n-2}{3}\right) ! 3^{1 / 2}|T|^{m+\frac{n}{3}-\frac{1}{6}}}{\left(m+\frac{n}{3}-\frac{1}{6}\right) ! 2 F_{20}^{m}+1 / 2}\left\{3^{\frac{1}{2}} H(T)+(-1)^{m+\left[\frac{n}{3}\right]} H(-T)\right\}, n \neq 3 s+2 \\
& =0 \text { for } n=3 s+2,
\end{aligned}
$$

where $\left[\frac{n}{3}\right]$ is the largest integer not greater than $\frac{n}{3}$.

$$
\begin{aligned}
& h_{0}\left(t-F_{00}\right)=\frac{1}{3^{1 / 2} F_{03}} \sum_{r=0}^{\infty} \frac{\partial^{r}}{a t^{r}} \sum_{\lambda=0}^{\infty} \sum_{\mu=0}^{\infty} \frac{\left(\lambda-\frac{1}{2}\right) !\left(\frac{\mu-2}{3}\right) !\left|t-F_{00}\right|^{\lambda+\frac{\mu}{3}-\frac{1}{6}}}{\left(\lambda+\frac{\mu}{3}-\frac{1}{5}\right) ! F_{20}^{\lambda+} 1 / 2_{F}(\mu-2) / 3} \\
& \text { - }\left\{3^{\frac{1}{2}} H\left(t-F_{C O}\right)+(-1)^{\lambda+\left[\frac{\mu}{3}\right]} H\left(F_{O O}-t\right)\right\} \sum_{p=0}^{2 \lambda} \sum_{q=0}^{\mu} G_{2 \lambda-p, \mu-q} F_{r, p, q} \text {, }
\end{aligned}
$$

where terms in which $\mu=3 s+2$ are absent. Also, the properties of $F_{r, p, q}$ imply that only those terms in which $\lambda+\frac{1}{3} \mu \geq 7 \mathrm{r} / 6$ are present. Hence

$(40)$

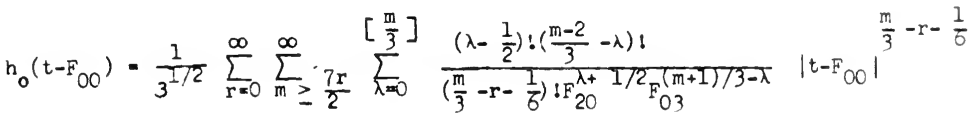

$$
\begin{aligned}
& \text { - }\left\{3^{\frac{1}{2}} H\left(t-F_{O O}\right)+(-1)^{r+\left[\frac{m}{3}\right]} H\left(F_{0 O}-t\right)\right\} \sum_{p=0}^{2 \lambda} \sum_{q=0}^{m-3 \lambda} G_{2 \lambda-p, m-3 \lambda-q^{F} r, p, q} \text {, }
\end{aligned}
$$

where terms in which $m=3 s+2$ are absent.

Consequently, the contribution to the asymptotic expansion of $\mathrm{J}$ is, by Frdélyi's theorem,

$$
\frac{e^{i k F} 00}{3^{1 / 2}} \sum_{m=0}^{\infty} \frac{e^{\frac{1 \pi}{2}}\left\{\left[\frac{m+2}{3}\right]+\frac{1}{2}\right\}}{k^{m / 3}+5 / 6} \sum_{\left|F_{20}\right|^{1 / 2}}^{2 m} \sum_{r=0}^{\left[\frac{m}{3}\right]+r} \sum_{\lambda=0}^{\frac{\left(\lambda-\frac{1}{2}\right) !\left(\frac{m-2}{3}+r-\lambda\right) !}{F_{20}^{\lambda} F_{03}^{(m+1) / 3+r-\lambda}}}
$$

(41)

$$
\text { - } \sum_{p=0}^{2 \lambda} \sum_{q=0}^{m+3 r-3 \lambda}{ }_{2} \therefore-p, m+3 r-3 \lambda-q F_{r, p, q} \text {, }
$$


where tems in wrich $m=3 s+2$ are absent.*
When $F_{20}<0, F_{03}>0$ we must replace $e^{\frac{i \pi}{2}}\left\{\left[\frac{m+2}{3}\right]+\frac{1}{2}\right\}$ by $e^{\frac{i \pi}{2}}\left\{\left[\frac{m+2}{3}\right]-\frac{1}{2}\right\}$

When $\mathrm{F}_{2 \mathrm{O}}>0$ and $\mathrm{F}_{\mathrm{O}_{3}}<0$ we only alter the sign of (4I).

When $\mathrm{F}_{20}<0$ and $\mathrm{F}_{03}<0$ we alter the sign of (il) and replace

$e^{\frac{i \pi}{2}}\left\{\left[\frac{m+2}{3}\right]+\frac{1}{2}\right\}$ by $e^{\frac{i \pi}{2}}\left\{\left[\frac{m+2}{3}\right]-\frac{1}{2}\right\}$.

6. Contributions from boundary stationary points

We consider in this article stationary points which lie on the boundary of $D$. The boundary is assumed to be an analytic curve in the neighborhood of $\left(x_{0}, y_{0}\right)$.

6.1 We consider first boundary stationary points $\left(x_{0}, y_{0}\right)$ at which $f(x, y)$ has a maximum or minimum relative to all neighboring interior and boundary points of D. To treat such a point our first step will be to make the boundary of $\mathrm{L}$ in the neighborhood of the point the axis of coordinates and, at the same time, to reduce the second-degree terms in the Taylor's expansion of $f(x, y)$ around the point to a sum of squares (see Fig. Il).

Let $\phi(x, y)=0$ be the equation of the boundary in the neighborhoor of $\left(x_{0}, y_{0}\right)$. We first introduce the linear transformation

$$
\begin{aligned}
& x-x_{0}=a h+b k \\
& y-y_{0}=c h+d k
\end{aligned}\left|\begin{array}{ll}
a & b \\
c & d
\end{array}\right|=1
$$

and choose $a, b, c$, d subject to the condition that $f_{h k}(0,0)$ vanishes. Hence $\mathrm{f}(\mathrm{x}, \mathrm{y})$ and $\phi(\mathrm{x}, \mathrm{y})$ become

$$
f(h, k)=f_{00}+f_{20} h^{2}+f_{02} k^{2}+\cdots
$$

Focke seems to have omitted the factor $i^{\tau}$ in his formule (153). Ctherwise his result for this case agrees with our formula (LI). 
and

$$
\phi(h, k)=\phi_{10} h+\phi_{01} k+\phi_{20} h^{2}+\phi_{11} h k+\phi_{02} k^{2}+\ldots .
$$

We mey also choose a and $c$ so that the sign of $\phi_{h}(0,0)$ is the sign of $\phi(x, y)$ in n, that is, so that the positive h-axis points into D.

If $\phi_{k}(0,0)$ is not zero it is possible to make a further transformation

$$
\begin{aligned}
& h=\frac{1}{d}\left(\phi_{10} f_{02} \bar{h}-\phi_{01} \bar{k}\right) \\
& k=\frac{1}{d}\left(\phi_{01} f_{20} \bar{h}+\phi_{10} \bar{k}\right),
\end{aligned}
$$

where $\mathrm{d}=\phi_{10}^{2} \mathrm{f}_{\mathrm{O} 2}+\phi_{\mathrm{O} 1}^{2} \mathrm{f}_{20}$, so as to make $\phi_{\mathrm{k}}=0$ and leave the form of $\mathrm{f}(\mathrm{h}, \mathrm{k})$ unaltered. Suppose $\left(x_{0}, y_{0}\right)$ is a relative minimum; then $f_{20}>0$ and $f_{02}>0$, so that $A \neq C$. As a corsequence of this trarisformation

$$
f(\bar{h}, \bar{k})=f_{0 O}+\bar{f}_{20} \bar{h}^{2}+\bar{f}_{02} \bar{k}^{2}+\ldots
$$

and

$$
\phi(\bar{h}, \bar{k})=\bar{\emptyset}_{10} \bar{h}+\bar{\phi}_{20} \bar{h}^{2}+\bar{\phi}_{11} \bar{h} \bar{k}+\bar{\phi}_{02} \bar{k}^{2}+\cdots \cdot
$$

Now $\phi(\bar{h}, \bar{k})=0$ is the original boundary curve. Let

(4h) $X=\sigma(\bar{h}, \bar{k}), \quad Y=\bar{k}$.

If we solve the equations (44) for $\bar{h}$ and $\bar{k}$ in terms of $X$ and $Y$ we obtain

$\bar{i}=a_{10} X+a_{20} X^{2}+a_{11} X Y+a_{02} Y^{2}$

$\bar{k}=\mathrm{Y}$.

We substitute in (43) and obtain

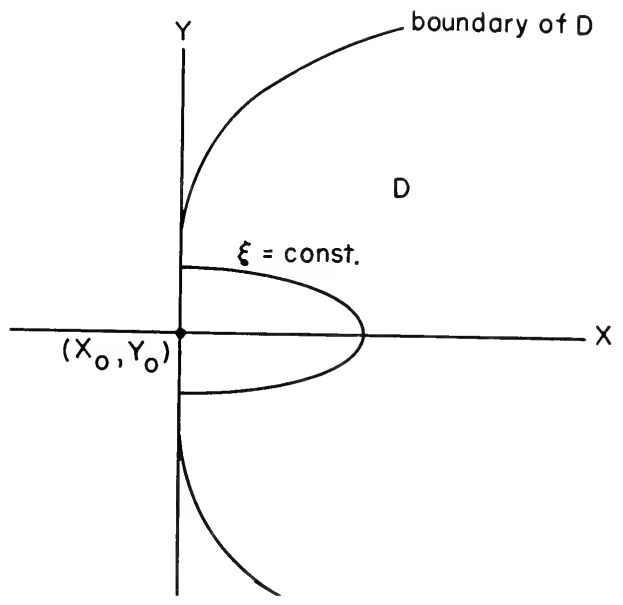

Fif. 11

* Th1s transformation is suggested by Focke [6], p. 46. 


$$
F(X, Y)=F_{00}+F_{20} X^{2}+F_{02} Y^{2}+\cdots,
$$

where $\mathrm{F}_{00}, \mathrm{~F}_{20}, \mathrm{~F}_{02}, \ldots$ are new coefficients and where we have changed the functional symbol to accord with earlier notation.

The above sequence of transformations has transformed the original boundary to $X=0$ while achieving the form $(45)$ for $F(X, Y)$.

We now proceed as in Section 5.1 except that $X_{0}=0, Y_{0}=0$, and the limits of integration are from $-\frac{\pi}{2}$ to $\frac{\pi}{2}$. We obtain for this case

$$
h_{0}\left(t-F_{00}\right)=\frac{1}{2\left(F_{20} F_{02}\right)^{1 / 2}} \sum_{m=0}^{\infty} \frac{\left(t-F_{00}\right)^{\frac{m}{2}}}{(m / 2) !} \sum_{r=0}^{m} \sum_{\mu=0}^{\left[\frac{m}{2}+r\right]} \frac{\left(\mu-\frac{1}{2}\right) !\left(\frac{m}{2}+r-\mu-\frac{1}{2}\right) !}{F_{20}^{m} / 2+r-\mu_{F}^{\mu}}
$$

$$
\cdot \sum_{p=0}^{2 r-2 \mu+2 m} \sum_{q=0}^{2 \mu} G_{2 r+m-2 \mu-p, 2 \mu-q} F_{r, p, q},
$$

where $[\mathrm{p}]$ is the largest integer not greater than $\mathrm{p}$.

Therefore the corresponding asymptotic expansion is

$$
\frac{e^{i k F_{00}}}{2\left(F_{20} F_{02}\right)^{1 / 2}} \sum_{m=0}^{\infty} \frac{e^{i \frac{\pi}{2}\left(1+\frac{m}{2}\right)}}{k^{1+m / 2}} \sum_{r=0}^{\mu} \sum_{\mu=0}^{\left[\frac{m}{2}+r\right]} \frac{\left(\mu-\frac{1}{2}\right) !\left(\frac{m}{2}+r-\mu-\frac{1}{2}\right) !}{F_{20}^{m / 2+r-\mu} F_{02}^{\mu}}
$$

$$
\cdot \sum_{p=0}^{2 r-2 \mu+m} \sum_{q=0}^{2 \mu} G_{2 r+m-2 \mu-p, 2 \mu-q} F_{r, p, q} \text {. }
$$

If $\left(\mathrm{x}_{0}, \mathrm{y}_{0}\right)$ is a relative maximum, then $\mathrm{F}_{20}<0$ and $\mathrm{F}_{02}<0$ and the sign of (47) is also reversed. 
6.2 We suppose next that $\left(\mathrm{x}_{0}, \mathrm{y}_{0}\right)$ is a saddle point of $\mathrm{f}(\mathrm{x}, \mathrm{y})$ so that $\mathrm{f}_{\mathrm{xx}} \mathrm{f}_{\mathrm{yy}}-\mathrm{f}_{\mathrm{xy}}^{2}<0$. We introduce the same sequence of transformations used in Section 6.1 to obtain the form $(45)$ for $F(X, Y)$ while making the boundary curvo the Y-axis ${ }^{*}$ (see F1g. 12). We ruppose first that $F_{20}>0$ and $F_{02}<0$.

We now follow the treatment of the interior saddle-pcint as in rection 5.2 except that the paths of integration lie only in the first and fourth quadrants. Hence we may neglect only those terms in the Taylor's expansion of $\frac{(-1)^{r}}{r !} G(X, Y) F_{1}^{r}(\lambda, Y)$ (compare (35)) which contain odd powers of $Y$. Instead of (36) we obtain

$(4,8)$

$$
\begin{aligned}
h\left(t-F_{00}\right)=-2 \sum_{r=0}^{\infty} \frac{\partial^{r}}{\partial t^{r}} \int_{\left(t-F_{00}\right)^{1 / 2}}^{d} & \frac{\sum_{\lambda=0}^{\infty} \sum_{\mu=0}^{\infty} \eta^{\lambda}}{\frac{\lambda}{\left(F_{20}\right)^{1 / 2}} \frac{\left(F_{20} \eta^{2}-t+F_{00}\right)^{\mu-1 / 2}}{2 F_{02}\left(-F_{02}\right)^{\mu-1 / 2}}} . \\
& \sum_{p=0}^{\lambda} \sum_{q=0}^{2 \mu} G_{\lambda-p, 2 \mu-q} F_{r, p, q} d \eta .
\end{aligned}
$$

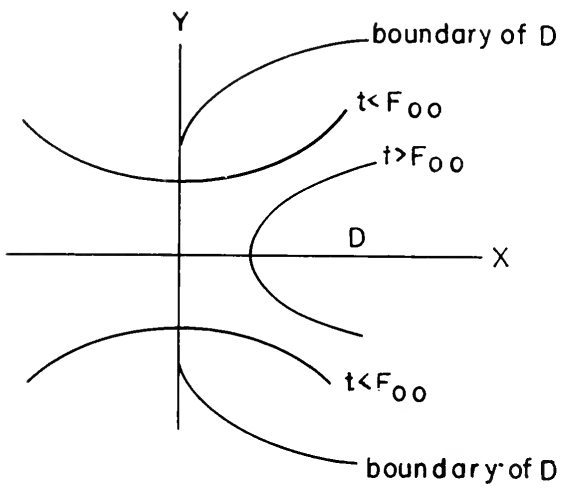

Fig. 12

*In this saddle point case it no longer follows that $\$ 0$. be ascume that d 70 ; this assumption means that the boundary of the domain $D$ does not coincide with either asymptote of the $f$ amily of hyperboles $f_{20}\left(x-x_{0}\right)^{2}+f_{11}\left(x-x_{0}\right)\left(y-y_{0}\right)+f_{02}\left(y-y_{0}\right)^{2}=$ const. 
Integrals of the type appearing in (48) were already considered in Section 5.2. Evaluation of $(48)$ and the application of Theorem 4 of the Appendix leada to $(47)$ except that $\left(\mathrm{F}_{2 \mathrm{O} \mathrm{F}_{2}}\right)^{1 / 2}$ is replaced by $\left|\mathrm{F}_{20} \mathrm{~F}_{02}\right|^{1 / 2} /$ i. This result also holds when $\mathrm{F}_{2 \mathrm{O}}<0$ and $\mathrm{F}_{\mathrm{O} 2}>0$.

\section{Remarks on the method}

For the benefit of those readers who may have been following some of the general theory of asymptotic solution of Maxwell's equations being developed at New York University we shall relate this theory to that of the present paper. A prime objective of the general theory has been to derive the asymptotic form of time harmontc solutions of Maxwell's equations (or the scalar second order hyperbolic equation) from conditions imposed on the coefficients of the differential equations and the initial and boundary conditions. Of course these conditions would be immediately related to the physical conditions of the problem. To derive this asymptotic series as well as to calculate it this theory uses the concept of the pulse solution of Maxwell's equations. By determining the behavior of the pulse solution a function of $x, y, z$, and $t$, in the neighborhood of each of its singularities with respect to $t$ one can write down at once by means of a general theorem the asymptotic series solution of Maxwell's equations [13]. Given the problem of obtaining the asymptotic form of the integrals considered in this paper, one can write down the corresponding pulse solution, proceed to determine its behavior in the neighborhood of Its singularities, and then apply the general theorem to obtain the asymptotic form of the integrals. There is, of course, a contribution to this asymptotic value from each singularity of the pulse solution.

The present paper, as has been seen, throws the problem of evaluating the double Fourier integrals asymptotically back to the problem of the single Fourier integral and the utilizes Erdélyi's theorem. The function $h(t)$ of the present paper is precisely the pulse solution of the peneral theory though it is not obtained in the 
$-37-$

same way as in the general theory. Moreover, as this paper shows the singularities of $h(t)$ are the critical points of the double integral. Insofar as theory is concorned, the present paper is more general in some respects and less general in others with respect to the kinds of critical points it can handle. However the present paper is decidedly more efficacious in calculating the asymptotic series which corresponds to each critical point. In the present method one proves more readily that the contribution of each critical point to the asymptotic value of the double integral is determined by a small neighborhood of the critical point and by using the form (14) for $h_{0}(t)$ one obtains more expeditiously the actual asymptotic expansion contributed by each critical point. 


\section{Appendix}

In this appendix we consider the asymptotic expansion of a Fourier integral in which the integrand has a logarithmic singularity. The analysis runs along lines similar to those followed by Erdélyi [7].

$$
\begin{aligned}
& \text { Firstly we discuss } \\
& \qquad I=\int_{\alpha}^{\beta} e^{1 k t}(t-\alpha)^{\lambda-1} \phi(t) \log (t-\alpha) d t,
\end{aligned}
$$

where $0<\lambda \leq 1, \phi(t)$ is $N$ times continuously differentiable for $\alpha \leq t \leq \beta$, and $\phi^{(n)}(\beta)=0$ for $n=0,1, \ldots, N-1$.

Let

$$
x_{0}(t)=e^{i k t}(t-\alpha)^{\lambda-1} \log (t-\alpha)
$$

and

$$
x_{n}(t)=\int_{t}^{i \infty} x_{n-1}(u) d u
$$

where the path of integration is defined by $u=t+1 y(y \geq 0)$. The integral then converges absolutely.

Repeated integration by parts of I gives

$$
I=\sum_{n=0}^{N-I} \phi^{(n)}(\alpha) x_{n+1}(\alpha)+\int_{\alpha}^{B} \delta_{n}^{(t)} \phi^{(N)}(t) d t .
$$

Now

$$
x_{n}(t)=\int_{0}^{\infty} 1 x_{n-1}(t+i y) d y=\frac{e^{\frac{1}{2}} i n \pi}{(n-1) !} \int_{0}^{\infty} y^{n-1} x_{0}(t+i y) d y
$$

by repeated interchange of the order of integration. Hence

$$
x_{n}(t)=\frac{e^{\frac{1}{2}} i n \pi}{(n-1) !} e^{i k t} \int_{0}^{\infty} y^{n-1} e^{-k y}(t+i y-\alpha)^{\lambda-1} \log (t+i y-\alpha) d y .
$$

Therefore 
$-39-$

$$
x_{n}(a)=\frac{e^{1 k a+\frac{1}{2} 1 \pi(n+\lambda-1)}}{(n-1) !} \int_{0}^{\infty} y^{n+\lambda-2} e^{-k y}\left\{\frac{1}{2} i \pi+10 F y\right\} d y \text {. }
$$

Since

$$
z !=\int_{0}^{\infty} y^{z} e^{-y} d y,
$$

(AB)

$$
z !^{\prime}=\int_{0}^{\infty} y^{z} e^{-y} \log y d y .
$$

Thus

$$
\int_{0}^{\infty} y^{2} e^{-y} \log y d y=2 ! \mathbf{y}(z)
$$

where

$$
Y(z)=\frac{z !}{z !} .
$$

The properties of the -function are well known. For example,

$$
\mathbf{Y}(z+1)=\frac{1}{z+1}+\mathbf{Y}(z)
$$

and

$$
Y(c)=-\varphi,
$$

where $\gamma$ is Euler's constant.

Employing (A3) we obtain

(AL) $\quad X_{n}(a)=\frac{e^{i k a+\frac{1}{2} i \pi(n+\lambda-1)}(n+\lambda-2) !}{(n-1) ! k^{n+\lambda-1}}\left\{\frac{1}{2} i \pi-\log k+1(n+\lambda-2)\right\}$.

Al $=0$

$$
|t+1 y-a|^{\lambda-1} \leq(t-a)^{\lambda-1}
$$

and 


$$
\begin{aligned}
|\log (t+i y-\alpha)| & =\left|\log (t-\alpha)+\log \left\{1+\frac{y^{2}}{(t-\alpha)^{2}}\right\}^{1 / 2}+1 \tan ^{-1} \frac{y}{t-\alpha}\right| \\
& \leq \frac{1}{2} \pi+\log (t-\alpha)+\log \left\{1+\frac{y^{\lambda / 2}}{(t-\alpha)^{\lambda / 2}}\right\}^{2 / \lambda} \\
& \leq \frac{1}{2} \pi+\log (t-\alpha)+\frac{2 y^{\lambda / 2}}{\lambda(t-\alpha)^{\lambda / 2}} .
\end{aligned}
$$

Hence, from (A2),

$$
\left|x_{n}(t)\right| \leq \frac{(t-\alpha)^{\lambda-1}}{k^{n}}\left\{\frac{1}{2} \pi+\log (t-a)\right\}+\frac{2(t-\alpha)^{(\lambda / 2)-1}\left(n+\frac{1}{2} \lambda-1\right) !}{\lambda k^{n+\lambda / 2(n-1) !}} .
$$

Therefore

$$
\int_{\alpha}^{\beta} X_{N}(t) \phi^{(N)}(t) d t=O\left(k^{-N}\right)
$$

Combining (AL), (A4) and (A5) we obtain:

\section{Theorem 1}

If $\phi(t)$ is $N$ times continuously differentiable for $\alpha<t \leq \beta$, $\phi^{(n)}(\beta)=0$ for $n=0,1, \ldots, N-1$, and $0<\lambda \leq 1$, then

$$
\begin{aligned}
& \int_{\alpha}^{\beta} e^{i k t}(t-\alpha)^{\lambda-1} \phi(t) \log (t-\alpha) d t \\
& =\sum_{n=0}^{N-1} \frac{e^{1 k \alpha+\frac{1}{2} i \pi(n+\lambda)}(n+\lambda-1) !}{n ! k^{n+\lambda}}\left\{\frac{1}{2} i \pi-\log k+\Psi(n+\lambda-1)\right\} \phi^{(n)}(\alpha)+O\left(\frac{1}{k^{N}}\right) .
\end{aligned}
$$

Similarly we can prove:

\section{Theorem 2}

If $\phi(t)$ is $N$ times continuously differentiable for $a \leq t \leq \beta$, $\phi^{(n)}(a)=0$ for $n=0,1, \ldots, N-1$, and $0<\mu \leq 1$, then 


$$
\begin{aligned}
& \int_{\alpha}^{\beta} e^{i k t}(\beta-t)^{\mu-1} \phi(t) \log (\beta-t) d t \\
& =\sum_{n=0}^{N-1} \frac{e^{i k \beta+\frac{1}{2} i n(n-\mu)}(n+\mu-1) !}{n ! k^{n+\mu}}\left\{Y(n+\mu-1)-\log k-\frac{1}{2} i \pi\right\} g^{(n)}(\beta)+O\left(\frac{1}{k^{N}}\right) .
\end{aligned}
$$

When $\phi$ does not vanish at olther end of the integral the introduction of a neutralizer enables us to deduce the afymptotic expansion from the preceding reculte. Since the use of the neutralizer has been described by Erdély1 we shall quote the theorem obtained. It is

\section{Theorem 3}

If $\emptyset(t)$ is $\mathrm{N}$ times continuously differentiable for $\alpha \leq t \leq \beta$ and $0<\lambda \leq 1,0<\mu \leq 1$, then

$$
\begin{aligned}
& \int_{\alpha}^{\beta} e^{1 k t}(t-\alpha)^{\lambda-1}(\beta-t)^{\mu-1} \phi(t) \log (t-\alpha) d t \\
& -\sum_{n=0}^{N-1} \frac{e^{i k \alpha+\frac{1}{2} i \pi(n+\lambda)}(n+\lambda-1) !}{n ! k^{n+\lambda}} \\
& \text { - }\left\{\frac{1}{2} i \pi-\log k+y(n+\lambda-1)\right\} \frac{d^{n}}{d a^{n}}\left\{(\beta-\alpha)^{\mu-1} q(\alpha)\right\} \\
& +\sum_{n=0}^{N-1} \frac{0^{i k \beta+\frac{1}{2} i \pi(n-\mu)}(n+\mu-1) !}{n ! k^{n+\mu}} \\
& \text { - } \frac{d^{n}}{d \beta^{n}}\left\{(\beta-\alpha)^{\lambda-1} \phi(\beta) \log (\beta-\alpha)\right\}+O\left(\frac{1}{k}\right) \text {. }
\end{aligned}
$$

Pinally, we consider what happens when the logarithic singularity occurs at an interior point. We restrict attention to

$$
\int_{\alpha}^{\beta} e^{1 k t} \phi(t) \log (t-c) d t,
$$


where $\alpha<c<\beta$ and $\operatorname{lcg}(t-c)$ is defined to be $\log |t-c|+1 \pi$ when $t<c$. From Theorem 3,

$$
\begin{aligned}
& \int_{c}^{\beta} e^{i k t} \phi(t) \log (t-c) d t \\
& =E_{\beta}+\sum_{n=0}^{N-1} \frac{e^{i k c+\frac{1}{2} i \pi(n+1)}}{k^{n+1}}\left\{\frac{1}{2} i \pi-\log k+I(n)\right\} \emptyset^{(n)}(c)+O\left(k^{-N}\right) ; \\
& \int_{a}^{c} e^{1 k t} \phi(t) \log (t-c) d t \\
& =E_{a}+\sum_{n=0}^{N-1} \frac{e^{i k c+\frac{1}{2} i \pi(n-1)}}{k^{n+1}}\left\{Y(n)-\log k-\frac{1}{2} i \pi\right\} \phi^{(n)}(c) \\
& +1 \pi \sum_{n=0}^{N-1} \frac{e^{i k c+\frac{1}{2} i n(n-1)}}{k^{n+1}} \phi^{(n)}(c)+O\left(k^{-N}\right),
\end{aligned}
$$

where $E_{\alpha}, E_{\beta}$ represent contributions from the end-points $\alpha$ and $\beta$ respectively. fdding these two equations we obtain:

Theorem 4

If $\emptyset(t)$ is $N$ times continuously differentiable for $a \leq t \leq \beta$, then

$$
\int_{\alpha}^{\beta} e^{i k t} \phi(t) \log (t-c) d t=E_{\alpha}+E_{\beta}+O\left(k^{-N}\right)
$$

and

$$
\int_{\alpha}^{\beta} e^{i k t} \phi(t) \log |t-c| d t=E_{\alpha}+E_{\beta}+i \pi \sum_{n=0}^{N-1} \frac{e^{1 k c+\frac{1}{2} i \pi(n+1)}}{k^{n+1}} \phi^{(n)}(c)+O\left(k^{-N}\right) .
$$




\section{Heferences}

[1] Wolf, F.

[2] Bremmer, H.

[3] Berphuis, J.

[4] Van Kampen, N.G.

[5] Bremmer, $\mathrm{H}$.

[6] Focke, J.

[7] Erdelyi, A.

[8] Luneberg, R.K.

[9] Van der Pol, B. and Bremmer, $\mathrm{H}$.

[10] Braun, G.

[1]] Courant, R.

[12] Siegel, K.M.,et.al.

[13] Kline, M.

[14] Kontorovitch,M.I. and Muravév, U.K.
- The diffraction theory of aberrations; keports on Frogress in Fhysics, V. XIV, 1951, np. 95-120, The Physical Society, London.

- Difraction problems of microwave optics; I.R. E. Trans.on antennas and propation, V.AF-3, 1955, pp. 222-228.

- The method of critical regions for two-dimensional integrals and its application to a problem of antenna theory; Ph. $)$. Thesis, 1955, University of Delft.

- An asymptotic treatment of diffraction problems; Fhysica, v. XIV, 1949, rp. 575-589 and V.XVI, 1950, pp. 817-21.

- On the asymptotic eveluation of diffraction integrals with a special view to the theory of defocusing and optical contrast; Fhysica, V.18, 1952, pp. 469-1.85.

- Asymptotische Entwicklungen mittels der Methode der stationären Fhase; Berichte Über die Verhardlungen der sächisischen Akademie der Wissenschaften zu Leipzig, V. 101, Heft 3, 1954, pp. 1-48.

- Asymptotic expansions; Technical Report 3, O.N.R. 1955. See also Asymptotic representations of Fourier integrals and the method of staionary phase; Jounr. Sci. Indust. Appl. Math., V.3, 1955, Fp. 17-27.

- Mathematical theory of optics; V. II, p. 370, Brown Univ., 1944.

- Operational calculus; Cambridge Univ. Press, Cambridge, 1950 , p. 82.

- Zur Methode der stationären Phase; Acta Phy sica Austriaca, v. $10,1956, \mathrm{pp}$. 8-33.

- Differential and integral calculus; Blackie and Son, Ltd., Glasgow, 1937, V.II, p. 152.

- Bistatic radar cross sections of surfaces of revolution; Jour. Appl. Phys., V.26, 1955, p. 299.

- Asymptotic solutions of Maxwell's equations involving fractional powers of the frequency; Comm. Pure and Appl. Math., v.8, 1955, pp. 595-614.

- Derivation of the laws of reflection of geometrical oftics on the basis of an asymptotic treatment of the diffraction problem; Jour. of Tech. Physics, Vol. XXII, No. 3, 1952, pp. 394-407. 
Comander

A1r Force Missile Test Center

Patrick Alr Force Kase, Jorida

ATTN: Tectinical Library

Comander

A1r Resmarch and Development Comand

isstinetton 25, D.C.

ATriv: PDDI

Comnander

Air Fesearch as.d De elopment Comand

Washington $25, D . C$.

ATTN: Lt. CO1. F. Bowker, RDIDRC-1

D1rector

Air University Library

Maxwell Air lorce ase, Alabama

ATI: CR -4582

Headquarters, USik

D1rector of Hesearch and Development

Wastington 25, D.C.

ATA: ArD?

Comander

wright Air Development Center

Wrlcht-Patterson Air Force Base, Chio

A TTN: Mr. Walter J. Portune, WCLils-6

Commander

wright Alr Development Venter

Wripht-Fatterson Air force dase, Chio

ATH: NCLNT-5, N. Draranjac

Commander

Wright Air Development Center

Wright-Patterson Air Force Base, Chio

ATTN; WCIRL-5, Wave trop. Section

Air Technical Intell1, tence Center Wricht-Patterson Air Force Base, Ohio ATT: AFIN-L,Bia

Comander

Rome Air Development Center

Griffiss Air force Hase

Rome, New York

AT TN: $\operatorname{ticSS}-3$

Commander

Rome Alr Develofnent Center

arifiss Air force ilase

Rome, New York

ATT: RCERA-1, D. Nather

Commander

Rome Air Development Center

Griffiss Air borce Base

Rome, New York

ATT: RCLR, Dr. Eurgess

\section{Commander}

Holloman Air Res. and Dev. Center Holloman Afr Force Base, New Mexico ATT: $H D O I$

Director

Evans S1 gnal Laboratory

Belmar, liew Jersey

ATTN: M. C.C. Woodyard

Director

Evans S1gnal Laboratory

Belmar, New Jersey

AT'N: Technical Document Center

S1 mal Corps Llaison Officer

Mas 3. Institute of Techology

Carbridre 39, Massachusetts

ATTN: A.D. Redrosian

Comanding ieneral

SC Enpineering Laboratories

Fort Monmouth, New Jersey

AfTi: SCLL Termical Documents Center Bay 2C122

Department of the nirmy

Cfflce of the Chief Simel fficer

viashinpton 25, I. .

ATTN: SIO D
(UNE copy unless ot:ariso noted)

Terartmes:t of the Army

offlce of. Chiter Signal officer

Enpineorin. and Tech. Muleion

washinet $n 25, D \cdot C$.

A. II: SICWET-S

Dire:tor

Da11stics hosearch Laboratory

Aterieen Frovini Ground, Marylatk

ATCN: Fallistice Measurement iah.

Ballistic fiesearch lab retories

Aherdeen Frovinp iround, Maryland

ATTi: Techical Information Eranch V1ctor in. Richard

Dfamond Ordrance Fuze Laboratorjes Washinpton $25, D . C$.

ATIN: tuided Missile Fuze Lthrary F.D. Hatcher, Chief Miscrave Develonment Section

(10)Document Service Center

Armed Services Tech. Information hpency

Knott Futlding

Dayton 2, Ohso

ATTN: DSC $-S C$

Offlce of Technical Services

Department of Commerce

Washington 25, D.C.

ATTH: Tech. keports section

National Bureau of Stardards

Department of Comerce

Washinirton 25, D.C.

ATI: Dr. A. Mellieh

National Bureail of Standards

Department of Comerce

Washiniton $25, \mathrm{D}, \mathrm{C}$.

ATTN: Custave Shapiro

Boulder Laboratories Library

National Burear. of Sta: car is

Poulder, Colorado

ATTN: Mrs. Victorła S. Barker, Lib.

Director

National Bureau of Standards

Central Radio irop. Laboratory

Boulder, Colorado

ATTN: Division 11.0

Library

Division of Fublic Documents

U.S. Government Frinting Office

washington 25, D.C.

(2) Commanier

Air Force Cambridge Research Center

La urence O. Hanscom Field

Bedford, Maes.

ATTN: Electronics Document Room CROOTH $-2 \mathrm{E}$

\section{(3) Corma nder}

Air Force Cambridge Restarch Center

Laurence G. Hanscom F1eld

Bedford, Mass.

ATTN: CRHD-R.E. Hiatt

(10) Commander

L. G. Hanscon Alr Field

Bedford, Mass.

CROOTH -2

Chief, Bureau of Aeronautics

Department of the Navy

hashinton 25, D.C.

ATT: Code Aer-TL-L14

Chief, treau of Ships

Navy Department

Washin riton 25, D.C.

ATR:: Mr. E. Johnstion, Code 838

Comander

U.j. Naval Alr Kissile lest Center

Foint Mgru, California

hTTi: Corde $366 ; 27-6$
U.S. Navel Ordnance Lat oretory

inl te lak.

Silver Apring 1\%, Marylard

A?T: The Litrary

Commander

11.3. Naval irdrance

Test jtation (Code 753)

China Lake, "allfomis

Librarion

U.S. Naval Postpraduate School

Monterey, Callferna

Director

U.S. haval hejearch Laboretor

Washingten $25, \ldots$.

AT lie: Code îlo

Director, National vecurity Agency washington $25,1 . C$.

Director

U.S. Navai hastarch Laboratory

washnoten $25,0$.

hin: Code $2(21$

Director

U. S. Laval research. Laboratory

Washington $25, \mathrm{D} . \mathrm{C}$.

ATL: Code 525C, J. Fohnert

Connanding Officer and Director

U. Navy inderwater jound Lab.

fart Trunbull, New Lendon, Conn.

A.TI: $\mathrm{Mr}_{\mathbf{r}}, \mathrm{C} . \mathrm{M}$. Dusn

Chief of thaval hesearch

Navy Department

Washingtion 25, D.C.

ATT: Code 42 ?

(2) $\boldsymbol{C}$ manding officer and Director

0.3. Navy Electronics Lab. Lib.

San Diego 52, Jalifernia

Chief, Bureau of Ordnance

Navy Department.

Washington $25,0 . C$.

ATIN: Technical Library, Code Ad3

Mr. H.E. hex, Code ReSL

Chief, Bureau of Crdiance

Navy liepartment

washington 25, D.C.

ATTN: Mr. C.H. Jackson, Code Re9a

Chief, Rureau of Ordnance

Navy Department

Washington 25, D.C.

ATTi: L.E. Wellingford, Code Relu

Chief, Burean of Aeronautics

Department of the Navy

Washincton 25, D.C.

ATTN: Code Aer-EL-931

Chief Bureau of Ships

Navy Department

Washington 25, D.C.

ATTV: L.E. Shoenaker, Code 838D

(2) Comander

I.S. Naval Air Uevelopment Center

Johnsville, Fennsylvando

Convande:

U.S. Naval Air Test Center

Fatuxent River, Maryland

AT N: ET-315, Antenna Section

Naval Ordnance Laboratory

Corona, Californis

ATTN: Library

U. 3. Naval ordnance Lahcrat ury

Department of the $\mathrm{Navy}$

Corona, Cali:crnia

A TT: 'Dr. hotert L. Conger

1.S. Naval urinance Plant

Ind anapolis 18 , Indiana

ATh: AD-130 (Litrary)

Alrborne Instrirents Lab., Inc.

160 ld Country Koad

Minecla, New Yor

ATTi: Litrarian 
ACF Electronics

$800 \mathrm{~N}$. Pitt Street

Alexandria, Pennsylvania

ATTN: Tech. Library

American Machine and Foundry Company

Electronies D1 vision

1085 Commonweal th Avenue

Boston 15, Mass.

ATT: Technical Library

Mrs. Rita Moravesik, Librarian

Andrew Alford Consulting Engineers

299 Atlantic Avenue

Boston 10, Maesachusetts

ATTN: Dr. A. Alford

Battelle Memorial Institute

$505 \mathrm{King}$ Avenue

Columbus 1 , Ohio

ATTN: I-205 F -

Dr. Bernard H. List

Bell Aircraft Corporation

P.C. Box 1

Buffalo 5, New York

ATIN: Technical Librar

Mrs. Jasmine H. Nulcahey

Bell Telephone Labs., Inc.

Whippany, New Jersey

ATTN: Technical Information Lib.

Bendix Aviation Corporation

Pacific Division

11600 Sherman Way

North Hollywood, Calif.

ATT: Technical Library J.R. Breninger, Engr. Libraria

Bendix Radio

Div. of Bendix Aviation Corporation

East Joppa Road

Towson 4, Maryland

ATTN: Res. and Development Lab. (465) Chief Engineer

Bjorksten Research Laboratories, Inc.

P.O. Box 265

Madison 1, Wisconsin

Attn: F.B. Korsgard, Treasurer

Boeing Airplane Company

Pilotless Aireraft Division

Seattle lit, Washington

ATTN: Pilotless Aircraft Div. Iibrary R.R. Barber, Library Supervisor

Boeing Airplane Company

Wichita Division

Wichita, Kansas

ATTN: Kenneth C. Knight, Librarian

Boeing Airplane Company

Seattle Division

Seattle 2L, Washington

ATN: E.T. Allen, Librarian

Chance Vought Aircraft, Inc.

P.O. Box 5907

Dallas, Texas

ATIN: Engineering Library

Mr. H.S. White, Librarian

Convair, A Division of jeneral Iynamics Corp.

Fort Worth 1, Texas

ATTN: K.3. Brown, Div. Res. Librarian

Convair, Division of General Drnamics Cor oration

San Diego 12, California

ATIN: Engineerin Library

Cornell Aero. Laboratory, Inc.

1455 Genesee Street

Puffalo 21, New York

ATTN : Elmá T. Evans, Librarian

Dalmo Victor Company

1414 EI Camino Feal

San Carlos, California

ATTW: Dorothea Quigley, Tech. Libr.

Dorne and Margolin, Inc.

30 Sylvester Street

Weatbury, L.I., New York

Douglas Aircraft Company, Inc.

Long Beach Division

Lone 3each 1, California

ATTH: Engineering Library (c-250)
Douglas AIreraft Company, Inc. 827 Lapham Stzósi

El Segundo, California

ATIN: Engineerinz Library

Douglas Adrcraft Company, Inc. 3000 Orean Park Boulevard

Santa Monica, Californla

ATIN: Eq. Sec. Reference Filea, $\mathrm{Eq}$. Eng. A250

Douglas Aircraft Corporation

Tulsa, Oklahoma

ATTN: Technical Library

Electronic Defense Laboratory

P.O. Box 205

Mountain View, California

ATW: Library

Electronics Research, Inc.

2300 N. New York Avenue

Evansville, Indiana

ATT: B.H. Saldridge,

$$
\text { Engineering Supervisor }
$$

Emerson and Cuming, Inc.

869 Washington Street

Cant on, Mass.

ATTN: W.A. Cuming

The Emerson Electric Mfg. Company

8100 Florissant Avenue

St. Louis 21, Missouri

AT'N: Kr. E. Breslin, Emerson Engineering Library

Fairchild Aircraft

Division Fairchild Eng and Airplane Corp.

Hagerstown, Maryland

ATTi: Library

Farnsworth Electronics Company

Fort Wayne 1, Indiana

ATTN: Tochnical Library

Federal Telecommunication Labs.

500 Washington Avenue

Nutley 10, New Jersey

ATTN: Technical Library

Gabriel Electronics

Division Gabriel Company

Needham Heights, Mass.

ATTN: Miss Elaine Foss, Librarian

General Electric Company

Ithaca, New York

ATT: Advanced Electronics Center Library, John B. Travis

General Electric Company

Electronics Park

Syracuse, New York

ATTV: Mrs. Anne Damon, Documents LAbrarian, Documents Lib. Bldg. 3-ü3

General Precision Laboratory, Inc. 63 Bedford Foad

Pleasantille, New York

ATIN: Nrs. Mary G. Herbst, Librarian

Goodyear Alrcraft Corp.

1210 lassillon Road

Akron 15, Ohio

ATIN: Library D/120 Plant A

Gruman Aircraft Lngineering Corp.

Bethpage, L.T., New Yor

ATIN: Engineering Library, Plant No. 5

Hallicratters Corporation

440 West 5 th Avenue

Chicago, Illinois

ATTN: Library

Hoffman Laboratories, Inc.

Los Angeles, California

ATTiv: thrat.
Hughes Aircraft Company

Microwave Laboratory

Culver City, California

ATTN: Library, Building 12

M.D. Adcock, Head, Antenna Dept.

Hughes Alrcraft Company

Culver City, California

ATTN: Research and Development Lib.

Hycon Eastern, Ine.

75 Cambridge Parkway

Cambridge, Mass.

ATTN: Mr. S. Stein, Library

International Business Maclines Corp.

Military Products Division

590 Madison Avenue

New York 22, Wew York

ATTN: $\mathrm{Mr}$. C.F. McElwain

International Business Machines Corp. Military Froducts Division

Airborne Computer Laboratories

Vestal, New York

ATTN: Mr.J.J. Walsh, Dent. 528

Jansky and Bafley, Inc.

1339 Wisconsin Avenue, N.W.

Washinzton, D.C.

ATTN: Tech. Library, Delmer C. Ports

Henry Jasik, Consultin? Engineering

61 Second Street

Nineola, New York

Jet Propulsion Laboratory

4800 Oak Grove Drive

Pasadena, California

ATTN: I.E. NewLan

Martin Katzin and Co., Consultante

711 luth Street, N.W.

Washington 5, D.C.

Lincoin Laboratory

P.0. Box 73

Lexington 73, Massachusetts

AT TN: Henry Straus, Document Rm, A-229

Lockheed Alrcraft Corporation

Missile Systems Division

7701 Woodley Avenue

Van Nuys, Californie

ATTN: MSD Library -902 , Dept. 82-10 E.A. Blasi, Head, Antenna Lab.

Lockheed Aircraft Corporation

California Division

Engineering Library

Dept. 72-25, Plant A-1, Bldg, 63-1

ATTN: N.C. Harnois

The Glenn L. Martin Company

Denver, Colorado

ATTN: Wm. V. Foley, Engineering Lib.

The Glenn L. Martin Company

Baltimore 3, Maryland

AT T: Engine ring Library Antenna Design Group

Maryland Llectronic Mf . Corp.

5009 Calvert Road

College Park, Varyland

AT IN: H. Warren Cooper

Mathematical Reviews

80 Waterman Street

Providence 6, Rhode Island

The W.L. Maxon Corporation

460 West 34 th Street

New York, New York

ATT: Antenna Laboratory

MeDonnel1 Aircraft Corooration

Box 516

St. Louis 3, Missouri

ATIN: R.D. Detric

Engineering Library

MeMillan Laboratory, Inc.

Ipswich, Mas achuset ts

ATTN: Security Officer

Docune $t$ fioom

Meloar, Inc.

3000 Arliniton Boulevard

Falls Church, Virsinia

ATTN: Engtneérin, Technical Lib. 
Microwave Radietion Company

19223 So. Handiton Street

Gardena, Callfornia

ATN: Mr. Morris J. Ehrlich, tres.

Northrop A1rerart, Inc.

Englneeria, Department

IOCC E. Broadway

Hawthorne, Calffornia

ATTN: E.A. Freitas, injueerin Library, Plant III

North American Aviotion, Inc.

12 ? 14 Lakewood Boulevard

Downey, California

ATTN: Techical Librery, Dept. $991-4$

North American Aviation, Inc.

Los Angeles International Afrport

Los Anpeles 45, Callifornta

ATM: Englneerin: Techical File

Page Communications Engineers

$71 \mathrm{C}$ uth Street, N.W.

bashint on $5, D . C$.

ATTN: LAbrary

Philco Cor oration Fegearch Division $A$ and Lppincott Street

Priladelphia 34, Pa.

ATTH: Techndcal Library

P1ckard and Burns, Inc.

240 Highland Arenue

Needham 94, Mass.

ATTN: Dr. J.T. de Eettencourt

Polytechnic Research and Development Company, Inc.

$2 \mathrm{C2}$ Tiliary Street

Erooklyn 1, New York

AT2: Technical Librery

Radiation Enplneering Laboratory

Vaynard, Mass.

ATTi: Dr. John Ruze

Padiation, Inc.

P.C. Drawer 37

Melbourne, Forida

ATTN: Technical Library

M. M.L. Cox, Assion $=$ t

Project Englneer

Radio Corp. of America

RCA Laboratorles

Rocky Point, Niew Y rk

ATTN: P.S. Carter, Lab. Library

\section{RCA Laboretories}

Princeton, New Jersey

ATTN: Miss Fern Claak, Líbrarian

Research Library

FCA Defense Electronic Products Canden 2, New Jersey

ATTN: Kiss J.N. Steever, Lubrarian Litirary $1 \mathrm{C}-2$

(2) The Ramowooldridoe Corporation 5730 Artor Vitae Street

Los Angeles 45, Califomia

ATN: Marzaret Shitnah, Chief Librarian, Regearch and Levelopment Library

The Rand Corporation

via: SPAM Lialson Cffice

$2700 \mathrm{Na1n}$ Street

Sante Monica, California

AT Ti: Library

Rantic Cerporation

Carlatasos, Californis

ATTi: Technical Library

Raytheon Manufactur Comany

$Y$ and $R$ Divigion.

Bedford, Nassachusetts

ATni: Irvink joldstein

Paytheon Laboratery

Wayland, Massachusetts

A.TT: Document Iib.. John. E. Halsh Dept. 8774 , Antenna
Raytheon Manufa turin. Company

vayland Lakoratory

rayland, Massachusetts

A.Ni: Aiss kl1ce G. Anderson, Lib. Wayland library

Reputlic Aolstion Corjoration

farminfiale, L.I., New York

ATN: H. Stienlitz, Engineerin. Lib.

Fheem Nanufacturs ne Company

Fesearc? and Development

9236 East Hall focad

Downey, aldfurnia

AT R: J.C. Joerver

Ryan keronautical Company

San Diero, Californio

ATTN: Technical Library

Sanders Associates

137 vanal treet

lieshua, New Hampshire

ATN: N.F. W1ld, Library

Sandia Coryoration

P.O. Bax 5800

Classified Document Division

Altuquerque, New Vexico

Sperry Gyroscope Company

Greot lieck, L.I., New York

ATNi: Engineering Librar Florence W. Turnbul, EnfT. Lttrarian

Stanford Research Institute

Menlo Park, California

ATT: Engineering Document Library Mrs. Beatrice Gibson, Libr.

Sylvania Electric Company

100 Firgt Street

Waltham, Kass.

ATT: Lubrarian

Systems Laboratories Ccrporstion

15016 Ventura BIvd.

Sherman Caks, California

ATTW: Dr.W.C. Hoffman

Technical Fesearch iroup

17 Union Square west

New York 3, New York

A.S. Thoras, Inc.

161 Devonghire Street

Boston, Nass.

ATTN: A.S. Thomas

Westinghouse Electric Corp.

2519 Wilkens Arenue

Ealtimore 3, Naryland

ATTN: Engineering Library Kent M. Mack

Wheeler Laboratories, Inc.

122 Cutter Mill Raad

Great Neck, New York

ATTN: it. Harold A. Wheeler

Zenith Plastica Company

ox 92

ardena, California

ATTN: N.S.S. Oleegky

\section{Litrar}

Geophysical Institute

University of Alaska

College, Aleska

Electronfc Research Laboratory

Div. of Electronlc Enpineering

University of Californte

Ferkeley 4, California

ATN: $S$. Silver

Electrondos Research Laboratcry

232 Cory Hall

University of Celifornia

Berikeley L, California

ATn: J.H. Whinnerv

Califomia Institute o: Cechnolory

1201 E. Californla Stree.

tasudena, California

iTlii: Dr. Charles F. Papas
Carmeips. Institute of Technolory

P1tts urpt 13, Fennylvands

ATA: nltert E. Heine

School of Electricsl Encineering

Cornel1 Und zersity

Ithiea, liew $Y \subset \mathbf{r k}$

hil Ni: Dr. Henry G. Sooker

College of encinetrit.

Undversity of riorida

alneovile, Horida

ATTi: Engineuring clences Lubrary Irotessor M.H. Litour

En 1: eerin, Lxperiment station

seoria Inet1tute of Technolop

htlanta, Georifa

ATTi: "Georgla iech. Library Mrs. J.H. Croalend

Technical Keports Collection

Harvard University

Gordon MeKay Library

303A Plerce hall

Oxford Street

Cambridre 38, Vassachusetts

AT IN: Mrs. E.L. Hufschmidt, Librarion

Har:ard Colleve Coservatory

60 Garden Street

Cambridge, Massachuset ts

ATIN: Dr. Fred L. whipple

Serials Department - c2C-S Lubrary

University of Illinols

Urbana, Illinols

ATT: Engineering Litrary

Antenna Section

Electrical Engr. Feseerch laboratory

University of Illinols

Urbana, Illinois

ATT: EEKL LLbrary, Room 2l,, Dr. R.H. Duflamel

The Johns Hopkins University

Department of Physics

Baltimore 18, Maryland

ATTN: Frofessor Donald E. Kerr

Radiation Laboratory

Johns Hopkins University

1315 St. Faul Street

Baltimore 2, Maryland

Applied Physics Laboratory

The Johns Hopk1ns University

8621 Georpla Aven.e

S1lver Spring, Maryland

ATT: Document Library

Mrssechusetts Institute of Technolory

Research Laboratory of Electronica

Docunent Room 20B-221

Cambridere 39, Massachusetts

University of Mchiran

Electronic Defenge roup

Engineering Research Institute

Ann Artor, Michipan

ATW: J.A. Boyd, Supervisor

Whllow Run Labs., of the Englnecring

Research Institute

The University of Vichian

di1l ow Run Air ort

spsilanti, Kichiman

ATi: F.Y. Sierel, sead, Theory and finalysis enartinent

Univers1t of Wich1gan

Wilin Run Laboratorles

Willow Run Airport

Ypsilanti, Michi an

ATTN: Shelia Coon, Lubrarian

University of unnesota

Mnneapolis, Minnesota

Encineering Library

ATN: Hear Librarian

Microwate iabaratory

Hertrical Enrineering Fent.

Nort western Univergity

Evancton, Illinois

A.M: Prof. L. bear 
Antenna Laboratory

Department of Electrical Engineering Ohio State University

Columbus, Ohio

ATTN: Dr. T.E. Tice

Oklahoma University Research Found. Norman, Oklahoma

ATTN: Technical Library Professor C.L. Farrar

Nicrowave Research Institute 55 Johneon Street

Brooklyn 1, New Ycrk

ATIN: Dr, A.A. Oliner

Polytechntc institute of Brooklyn 55 Johns on Street

Brooklyn 1, New York

ATT: Microwave Research Institute

Syracuse University

Dept. of Electrical Engr.

Syracuse 10, New York

ATT: Technical Library

University of Texas

Electricil Engr. Research Lab.

P.0. Box 8026 , Univ. Station

Austin 12, Texas

ATTN: John R. Gerhardt

Dept. of Physics

University of Texas

Austin 12, Texas

ATT: Physics Library

Claude W. Horton

Tufts University

Medford 55, Massachusetts

ATTN: Research Lab. of Physical Electronics Professor Charles R. Mingins

University of Toronto

Dept. of Electrical Engineering

Toronto, Ontario, Canada.

ATTV: Prof. Yeorge Sinclair

University of Washington

Dept. of Electrical Engine ring

Seattle, Washington

ATIN: Prof. G. Held

Ionosphere Research Laboratory

Pennsylvania State College

State College, Pennsylvania

ATTN: Prof. A.H. Waynick, Director

Institute of Mathematical Science 25 Waverly Place

New York 3, New York

ATTN: Irs. JoAn Segal, Librarian

School of Electrical Engineering

Purdue University

La fayette. Indiana

ATTN: Professor F.V. Schultz

Department of Electrical Engineerin California Institute of Technology

AITN: Dr. Charles H. Papas

Electronics Division

Fand Corporation

1700 Main Street

Santa Monica, California

ATIN: Dr. Robert Kalabo

National Bureau of Stan dards

Washington, D.C.

ATIN: Dr.W.K. Saunders

Applied Mathematics and Statistics Lab. Stanford University

Stanford, Cal fornia

ATN: Dr. Albert H. Bowker

Department of Physics and Astronomy

Michi an State Iniversity

Eagt lansing, Michigan

ATT: Dr. A. Leitner
Univergity of Tennessee

Knoxville, Tennessee

ATIN: Dr. Fred A. Ficken

Californie Institute of Technology

1201 E. California Street

Pasadena, California

ATTN: Dr. A. Erdely1

Wayne University

Detroit Michigan

ATIN: Professor A.F. Stevenson

Mathematics Department

Stanford Untversity

Stanford, California

ATT: Dr. Harold Levine

University of Minnesota

Minneapolis 14 , Minnesota

ATTN: Prof. Paul C. Rosenbloom

Department of Mathematics

University of Pennsylvania

Philadelphia $4, \mathrm{~Pa}$.

ATTN: Professor Bernard Epstein

Applied Physics Laboratory

The Johns Hopkins University

8621 Geor 18 A venue

Silver Spring, Naryland

ATIN: Dr. B.S. Gouray

(2) Exchange and Gift Division

The Library of Congress

Washington 25, D.C.

Electrical En gineering Department Massachusetts Institute of Tech. Cambridge 39, Massachuset ts

ATTN: Dr. L.J. Chu

Nuclear Development Assoc. Inc. 5 New Street

White Plains, New York

ATTN: Library

Lebanon Valley College

Annville, Pennsylvania

ATW: Professor B.H. Bissinper

Dept. of Physics, Thaw Hall

University of Pittsburgh

Pittsburgh 13, $\mathrm{Pa}$.

ATIN: Dr. Edward Gerjuoy

Dept. of Physics

Amherst College

Amherst, Massachusetts

ATTN: Dr. Arnold Arons

California Institute of Tech.

Electrical Engineering

Pasadena, California

AT N: Dr. Zohrab A. Kaprielian

Dr. Rodman Doll

209A Emmet St.

Ypsilanti, Mchlgan

California Institute of Tech. Pasadena 4 , Californie

ATTN: Mr.'Calvin Wilcox

(3) Mr. Robert Brockhurst

Woods Hole ceanographic Inst.

Woods Hole, Massachuset ts

National Bureau of $S_{\text {tandards }}$

Boulder, Colorado

ATTN: Dr. R. ellet

Engineerin? Library

Plant 5

Gruman Aircraft Corp.

Hethpage, I.I., New Iork

ATTN: Ms. A.U. Gray

Ms. Jane sicanion

284 jouth street

Southbridge, Mas sachusetts

Dr. Solomon L. Schwetel

3689 Louis Road

Palo Alto, California
Microwave Laboratory

55 Johnson Street

Brooklyn, New York

ATTN: Dr. Bernard Lispmann

University of Minnesota

The University Library

Minneapolis 14, Minnesota

ATIN: Exchange Division

Professor Bernard Friedman

55 Hill top Avenue

New Rochelle, NewYork

Lincoln Laboratory

Massachusetts Institute of Tech.

P.O. Box 73

Lexington 73, Mass.

ATTi: Dr. Shou Chin tiang, Rm. C-35]

Melpar, Inc.

3000 Arlington Boulevard

Falls Church, Vircinia

ATIN: Mr. K.S. Kelleher, Section Head

Antenna Laboratory, ERD

HQ Air Force Cambrídge Research Center

Laurence $C$. Hanscom Field

Bedford, Massachusetts

ATTN: Nelson A. Logan

Electronics Research Directorate

HD Air Force Cambridge Research Center

Iaurence 6 . Hanscom Field

Pedford, Massacinsetts

ATTN: Dr. Philip Newman, CRRK

HQ Air Foree Cambridge Research Center

Laurence $C$. Hanscom Field

bedford, Massachusetts

ATTN: Mr. Francis J. Zucker

Crosley AVCO Research Labs.

257 Crescent Street

Waltham, Magsachusetts

ATTN: Mr. N.C. Lerson

Antenna Research Section

Microwave Laboratory

Hughes Aircraft Company

Culver City, California

ATTN: DT. Richard B. Barrar

Columbia University

Hudson Laboratories

P. Box 239

145 Palisade Street

Dobbs Ferry, New York

ATN : Dr. M.W. Johnson

Institute of Fluid Dymamics and Applied Math.

University of Maryland

College Park, Naryland

ATTN: Dr. Eiliott Montroll

Dept. of Electrical Engineering

Washington University

Saint Louis 5, Missouri

ATTN: Professor J. Van Blajel

Dept. of the Navy

Office of Naval Research Branch Office

1030 E. Green Street

Pasadena 1, California

Brandeis University

Waltham, Massachusetts

ATTN: Library

General Electric Company

Microwave Laboratory

Electronics Divigion

Stanford Industrial Park

Palo Alto, Califormia

AT TN: Isbrary

Hugheg kesearch Laboratories

Hughes Aircraft Company

Culver City, California

ATTN: Dr. W.A. Dolid

Bldg. 12, Rm. 2529

inyth Research Associates

3930 4th Avenue

AlW: Br. John B. Smyth 
Electrical En+1 neerin:

California Institute of Tuch.

Pasadena, Cellforni

ATN: Dr. Georges O. We11]

Naval Research Leiboratory

wash 1n,ton 25, I.C.

ATTN: Dr. Henry $\therefore$ lagserini Corte 5278 A

Dr. George hear

10585 N. Stelling R.d.

Cupertino, Californio

Brooklyn rolytechric Institute 85 It viniston $5+$ reet

Brooklyn, New Yor

ATR: : $r$, Natha" Yarcuviez

Department of Electrical En $\boldsymbol{x}$.

Brooklyn Folytechic Institute

85 Livingston Street

Brooklyn, New lork

ATTN: Dr. Jerry Smoys

Dept. of Mathematics

University of New Mexico

Albuquerque, New Kexico

ATTN: Dr. I. Kolodner

W. L. Maxon

$460 \mathrm{w}$. 34 th St reet

New York, N.Y.

ATT: Dr. Harry Hoctotadt 



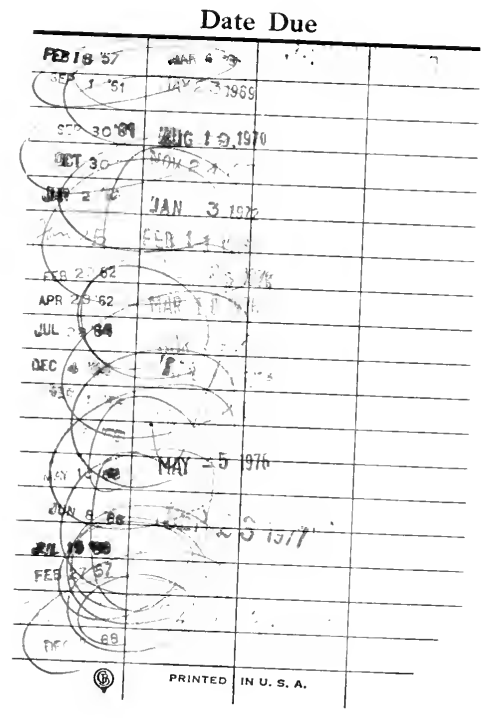




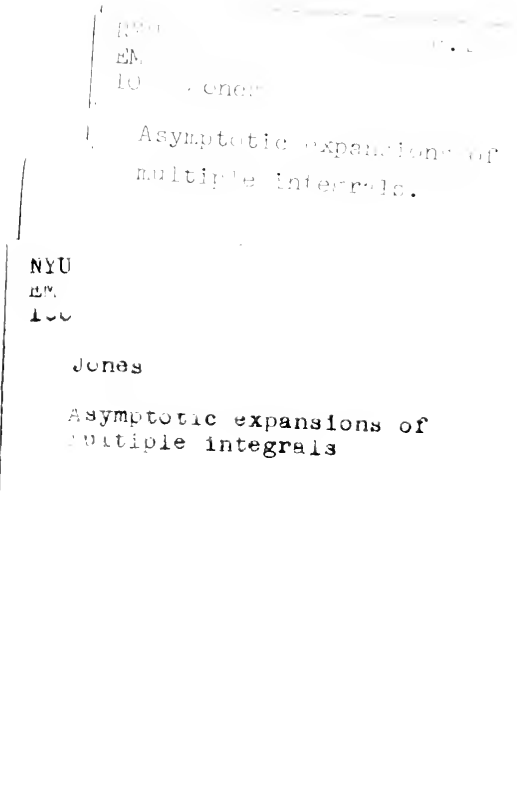


-

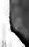

